\title{
Kontrollierte Ambivalenz. Theodor Fontanes Der Stechlin
}

Rund zehn Jahre nach Erscheinen des ersten Manifests der Modernen, der zehn Thesen der Freien litterarischen Vereinigung Durch! von 1886, schrieb Theodor Fontane seinen letzten Roman Der Stechlin. ${ }^{102}$ Im Roman lamentieren konservative Figuren über den sogenannten Fortschritt und die aufkommende Demokratisierung; Adelige dominieren das Figurenarsenal. Die Großstadt Berlin ist zwar einer der prägenden Schauplätze, in der Darstellung jedoch kaum vom ländlichen Anwesen Stechlin zu unterscheiden. Die Lebensweise der Figuren ist mehr oder weniger überall die gleiche; die Erzählweise und das Setting des Stechlin scheinen eher der Epoche des Realismus denn der Moderne zuzugehören. ${ }^{103}$

Was sich auf den ersten Blick als ein konservatives, dem Vergangenen zugewandtes Unterfangen präsentiert, ist entschieden an der Gegenwart ausgerichtet, behandelt Der Stechlin doch eine Vielzahl von Themen der Moderne. Explizit wird diese selbst reflektiert. ${ }^{104}$ Auch hinsichtlich der narrativen Verfahren nimmt Der Stechlin moderne Elemente auf. Nicht umsonst wird Theodor Fontane als „Dichter des Übergangs“ bezeichnet, was für den Stechlin ganz besonders zutriff.. ${ }^{105}$ Geschrieben wurde der Roman in den Jahren 1895

102 Das Manifest ist wiederabgedruckt in: Wunberg, Die literarische Moderne. Vgl. zum Manifest auch Kiesel, Geschichte der literarischen Moderne, 13-33.

103 Dass die Diskussion um die Rolle des Adels um die Jahrhundertwende durchaus aktuell war, zeigt Monika Wienfort, „Fontane und der Adel. Beobachtungen zum Stechlin“, Fontane-Blätter, Nr. 76 (2003): 126-133.

104 Die Selbstthematisierung der Moderne lässt sich als Kriterium für die Zugehörigkeit zu derselben verstehen. Diese ist „nicht ausschließlich an eine spezifische Schreibweise und Ästhetik, sondern auch an eine Haltung der gesellschaftlichen Moderne gegenüber zu knüpfen [...]. Moderne wäre sodann die kategorische und permanente Hinterfragung von Modernisierungsprozessen“. Kiesel und Becker, „Literarische Moderne. Begriff und Phänomen“, 13 .

105 Vgl. Patricia Howe, Hrsg., Theodor Fontane. Dichter des Übergangs. Beiträge zur Frühjahrstagung der Theodor Fontane Gesellschaft 2010, Fontaneana (Würzburg: Königshausen \& Neumann, 2013).

Gerade dieser Aspekt der Form, die heute als das eigentlich ,Moderne‘ von Fontanes Stechlin angesehen wird, gab Anlass zu Diskussionen über dessen literarische Qualität. Robert Walser gesellte sich zu den Bewunderern des Spätwerks und soll zu Carl Seelig in dessen Wanderungen mit Robert Walser gesagt haben: „Wie haben Gottfried Keller, 
bis 1897. Fontane veröffentlichte den Text zunächst in Fortsetzungen in der Zeitschrift Über Land und Meer. Im Oktober 1898, mit Impressum 1899, erschien Der Stechlin in Buchform im Verlag F. Fontane \& Co seines Sohnes.

In Briefen an Paul Schlenther und Carl Robert Lessing von der Vossischen Zeitung beschreibt Fontane den Stechlin als „politischen Roman“. ${ }^{106}$ Eine Behauptung, die sich nicht nur dadurch bestätigt sieht, weil die Figuren darin politisieren und politische Wahlen stattfinden, sondern auch, weil Politik in einem weiteren Sinn als das Verhandeln von Ordnungsmodellen verstanden werden kann. Die Oppositionen zwischen den Ständen, der Bedeutungswandel des Adels, das aufkommende Bürgertum und die Sozialdemokratie, die Soziale Frage sowie die Veränderungen von Geschlechterrollen sind im

C. F. Meyer und Theodor Fontane ihre schöpferischen Kräfte für das Alter aufgespart! Gewiß nicht zu ihrem Nachteil.“ Carl Seelig, Wanderungen mit Robert Walser (St. Gallen: Tschudy, 1957), 34 .

Thomas Mann bemerkte zum Stechlin: „Wenn Effi Briest in sozialethischer Hinsicht am weitesten über Fontanes Epoche hinausreicht, so ist es der Stechlin, der dies in artistischer Beziehung tut, der Wirkungen kennt, Kunstreize spielen läßt, die weit über allen bürgerlichen Realismus hinaus liegen." Thomas Mann, „Anzeige eines Fontane-Buches [1919]“, in Thomas Mann. Große kommentierte Frankfurter Ausgabe. Werke - Briefe - Tagebücher, hg. von Heinrich Detering u. a., Bd. 15.1: Essays II 1914-1926, hg. von Hermann Kurzke (Frankfurt am Main: Fischer Verlag, 2002), 271. In dieser ausführlichen Rezension zu Conrad Wandreys Theodor Fontane stimmt Mann in das Lob auf Effi Briest als Höhepunkt des Schaffens des Autors ein, verteidigt jedoch den Stechlin resolut gegen Wandreys Vorwurf von „Verfalls- und Verarmungsmerkmalen“. Mann, 269. Wandrey beobachtet am Stechlin eine Verselbstständigung der Sprache: „Fontanes Gesprächstechnik versagt, genauer, sie verselbständigt sich. Sie hatte bisher als bewährtestes Mittel seiner epischen Kunst immer im Dienst einer künstlerischen Idee gestanden, nun wird sie aus einem Mittel zum Selbstzweck. Das entscheidet dichterisch über Art und Wert des Stechlin." Conrad Wandrey, Theodor Fontane (München: C. H. Beck, 1919), 3olf. Interessanterweise leitet Wandrey daraus eine neue Lektürestrategie ab: „Des Wertvollen im Stechlin vermag sich erst der zu bemächtigen, der mit den stofflichen Vorgängen und Vorwänden des Buches bekannt ist und nun willkürlich auf ein beliebiges Kapitel zurückgreifen kann, um es losgelöst, in reinem Fürsichsein, zu genießen." Wandrey, 305.

Die gegensätzliche Bewertung des Stechlin als „Gipfel Fontanescher Erzählkunst“, als „ein zukunftsweisendes Romanwerk“ oder als „uferlose[s] Geplauder eines anekdotenliebenden Greises“ betont auch Christian Grawe noch 1987. Christian Grawe, „Fontanes neues Sprachbewußtsein in ,Der Stechlin“", in Sprache im Prosawerk. Beispiele von Goethe, Fontane, Thomas Mann, Bergengruen, Kleist und Johnson, 2. Aufl. (Bonn: Bouvier, 1987), 39. Fontane sei mit dem Stechlin ,auf dem Wege zum Roman des 20. Jahrhunderts“, der damit „eine neue Stufe seiner Romankunst“ erreiche und ein "neues Sprachbewußtsein“ entwickle, so Grawes Ansicht. Grawe, 43.

106 Brief an Paul Schlenther, Berlin, 21.12.1895 und Brief an Carl Robert Lessing, Karlsbad, 8.6.1896, beide in: Theodor Fontane, Der Stechlin. Roman. Kritische Ausgabe, hg. von Peter Staengle, Edition Text 1 (Frankfurt am Main, Basel: Stroemfeld, 1998), 395f. Im Folgenden als Sigle DS abgekürzt. 
Vorder- und im Hintergrund präsent und werden als Ordnungsprobleme greifbar. Der große Konflikt des Romans ist die Dynamik der Moderne, die mit Zygmunt Bauman als Zusammenspiel von Ordnung und Ambivalenz beschrieben wurde. In diesem Sinn ist Der Stechlin ein Ordnungsroman: Er hat Ordnung zum Thema, nimmt selbst eine ordnende Funktion in narrativer Hinsicht wahr und stellt diese Funktion wiederum zur Diskussion, indem er auf dieses Verfahren hinweist.

Das Politische am Roman ist auch seine Aktualität: Fontane verstand den Stechlin als "Zeitroman“, in den die Zeit, in der er verfasst wurde, eingeschrieben ist. Neben der Thematik des Modernen sind auch die Verfahren und die Form des Romans Der Stechlin durchaus geprägt von modernen Techniken. Darunter ist der Umstand zu zählen, dass es sich um einen "Sprachroman“ handelt, in dem die Handlung von sekundärer Bedeutung ist. ${ }^{107}$ Fontane beschreibt in einem häufig zitierten Briefentwurf an Adolf Hoffmann, den Herausgeber von Über Land und Meer, im Vorfeld der Publikation des Romans als Fortsetzungsgeschichte in der Zeitschrift, die Art und Weise des Erzählens folgendermaßen:

[D]ieser Stoff wird sehr wahrscheinlich mit einer Art Sicherheit Ihre Zustimmung erfahren. Aber die Geschichte, das was erzählt wird. Die Mache! Zum Schluß stirbt ein Alter und zwei Junge heiraten sich; - das ist so ziemlich alles, was auf 5 oo Seiten geschieht. Von Verwicklungen und Lösungen, von Herzenskonflikten oder Konflikten überhaupt, von Spannungen und Überraschungen findet sich nichts. ${ }^{108}$

Dieser Fokus auf die Erzählverfahren ist ein weiterer Hinweis auf die Modernität des Romans. In demselben Briefentwurf hebt Fontane hervor, dass dies die adäquate Form des Zeitromans sei: „Natürlich halte ich dies nicht nur für die richtige, sondern sogar für die gebotene Art, einen Zeitroman zu schreiben“" ${ }^{109}$

In der hier artikulierten Poetik, in der die Bedeutung des discourse unterstrichen wird, findet sich eine Position, die der Form eines Textes ebenso Bedeutung und Aussagekraft beimisst, wie dem Inhalt des Textes. Insofern lässt sich Fontanes vielzitierte Äußerung aus dem erwähnten Briefentwurf an

107 Thomas Mann spricht in seinem die Fontane-Rezeption prägenden Essay Der alte Fontane von einer zunehmenden „Verflüchtigung des Stofflichen“ in Fontanes Spätwerk. Thomas Mann, „Der alte Fontane“, in Thomas Mann. Große kommentierte Frankfurter Ausgabe. Werke - Briefe - Tagebücher, hg. von Heinrich Detering u. a., Bd. 14.1: Essays I. 1893-1914, hg. von Heinrich Detering unter Mitarbeit von Stephan Stachorski (Frankfurt am Main: Fischer Verlag, 2002), 262.

108 Brief an Adolf Hoffmann (Briefentwurf), Berlin, Mai oder Juni 1897, in: DS 398.

109 Brief an Adolf Hoffmann (Briefentwurf), Berlin, Mai oder Juni 1897, in: DS 398. 
Hoffmann, es handle sich beim Stechlin um eine "Idee, die sich einkleidet" ${ }^{\text {"110, }}$ auch mit Betonung auf das Einkleiden lesen. Das Einkleiden, so will es Fontane verstanden wissen, sei "[a]lles Plauderei, Dialog, in dem sich die Charaktere geben, und mit ihnen die Geschichte. ${ }^{\text {111 }}$ Auch die Hauptfigur des Romans, Graf Dubslav von Stechlin, „ließ sich gern was vorplaudern und plauderte selber gern." (DS 9) $)^{112}$

Im Stechlin wird zwar viel erzählt, aber kaum mit handlungstechnischer Substanz im Sinn von sich aufbauenden Sequenzen und Motivierungen. Dieses Erzählen rückt Fontane in die Nähe von Robert Walser, der für sein ereignisloses Erzählen und seine Plauderei bekannt ist. ${ }^{113}$ Wie sich im Verlauf der Analyse zeigen wird, sind Fontane und Walser gerade hinsichtlich der Kategorie der Ordnung in eine Relation zu bringen. Persifliert Walser die Ordnung und ihre realistischen Verfahren, indem er sie in metanarrative Widersprüche treibt, so versucht Fontane die Ordnung mit seinen dominanten Erzählverfahren vor dem Auseinanderbrechen zu bewahren; gerade dadurch betont er die ambivalente Verfassung ebendieser Ordnung, setzt doch gerade die Notwendigkeit, die Ordnung zu schützen, eine Gefährdung derselben voraus. ${ }^{114}$ Auch zu Franz Kafka sind Parallelen deutlich. Diese liegen im Modellhaften des Stechlin, das, wenn auch in anderer Absicht und Wirkung, in seinem

\footnotetext{
110 Brief an Adolf Hoffmann (Briefentwurf), Berlin, Mai oder Juni 1897, in: DS 398.

111 Brief an Adolf Hoffmann (Briefentwurf), Berlin, Mai oder Juni 1897, in: DS 398.

112 Zitiert wird Der Stechlin unter der Sigle DS nach der kritischen Ausgabe, die 1998 im Stroemfeld Verlag erschienen ist. Die Große Brandenburger Ausgabe wurde v. a. des Apparats wegen verwendet, vgl. Theodor Fontane, Der Stechlin, in Theodor Fontane. Große Brandenburger Ausgabe, hg. von Gotthard Erler, fortgeführt von Gabriele Radecke und Heinrich Detering, Bd. 1.17, hg. von Klaus-Peter Möller (Berlin: Aufbau, 2001). Beide Ausgaben geben den Erstdruck der Buchausgabe wieder, die Stroemfeld-Ausgabe dazu alle Varianten zu den Zeitschriftendrucken.

113 Vgl. dazu in Bezug auf den Stechlin und Jakob von Gunten: „Dieses um das Problem der Nullstelle kreisende Erzählverfahren rückt Theodor Fontane in die Nähe des fünfzig Jahre jüngeren Robert Walser; der alte Dubslav von Stechlin figuriert als ein Vorläufer Jakob von Guntens in Walsers gleichnamigem Berlin-Roman, der zehn Jahre nach dem Stechlin erscheint. Eine Genealogie der Moderne hätte folglich neben Walser entsprechend auch Fontane zu berücksichtigen.“ Ursula Amrein und Regina Dieterle, „Einleitung“, in Gottfried Keller und Theodor Fontane. Vom Realismus zur Moderne, hg. von Ursula Amrein und Regina Dieterle (Berlin, New York: De Gruyter, 2008), 11. Vgl. dazu auch: Margret Walter-Schneider, „Von Wetterfahnen, Schönheitskursen und Straßenmalern. Über das Moderne in Fontanes ,Stechlin“', in Gottfried Keller und Theodor Fontane. Vom Realismus zur Moderne, hg. von Ursula Amrein und Regina Dieterle (Berlin, New York: De Gruyter, 2008), 113-126.

114 So argumentiert auch Zygmunt Bauman, um die Beziehung zwischen Moderne und Ordnung darzustellen: Ordnung wird erst dann thematisiert, wenn sie prekär wird. Siehe Kap. 1.2.1 Ordnung und Ambivalenz (Bauman), S. 15ff. oben.
} 
Formbewusstsein an Kafkas Bau erinnert. Wie der Bau ein abgeschlossenes System darstellt, so scheint dies auch für den Stechliner Kosmos zu gelten. Fontane schließt also, insbesondere mit dem Stechlin, dezidiert an die moderne Literatur der Jahrhundertwende an und bereitet die spätere Auseinandersetzung mit Ordnung und Erzählung vor. ${ }^{115}$

Bei aller Betonung des Modernen und der Ambivalenz des Stechlin darf doch dessen genuine Ordnung und Ordentlichkeit nicht aus dem Blick geraten. Dabei fällt insbesondere das syntaktische Erscheinungsbild auf: 46 nummerierte Kapitel werden in der Buchpublikation zu neun mit Überschriften versehenen Teilen zusammengefasst, die mehrheitlich thematisch bindend sind. Die nummerierten Kapitel wiederum sind in mit drei Sternchen gekennzeichnete Abschnitte unterteilt, die zeitliche oder räumliche Sprünge markieren. ${ }^{116}$

Die erzählte Welt ist übersichtlich gestaltet und gliedert sich in zwei Handlungsräume - Grafschaft Ruppin mit Stechlin, Kloster Wutz und den Verbindungswegen sowie Berlin - und wenige Schauplätze, die untereinander verbunden sind. ${ }^{117}$ Die Erzählung ist geformt durch vielfältige Spiegelungs- und Symmetrieverhältnisse. Diese prägen mehrere Ebenen, reichen von Wiederholungen einzelner Wendungen und Worte, über thematische und motivische Verkettungen, bis zur Figurengestaltung und deren binären Beziehungen. ${ }^{118}$ Über dieses deutlich konturierte Beziehungsnetz wird versucht, der

115 Vgl. dazu Charlotte Jolles, die den Stechlin in engen Bezug zu Thomas Manns Zauberberg als typischem Roman der Moderne setzt: „Es ist die Obliegenheit dieses Romans, die Auflösung alter Ordnungen und das Hervortreten neuer Mächte in all ihren politischen, sozialen und kulturellen Aspekten aufzuzeigen, ebenso wie der Zauberberg es für eine spätere Zeit tut, wo die Desintegration bereits weiter fortgeschritten und die Spannungen explosiver geworden sind.“ Charlotte Jolles, „Der Stechlin'. Fontanes Zaubersee“, in Fontane aus heutiger Sicht. Analysen und Interpretationen seines Werks, hg. von Hugo Aust (München: Nymphenberger Verlagshandlung, 1980), 252.

116 Peter Demetz glaubt, dass es Fontane darum ging, „die inneren Ansätze einer Gliederung graphisch zu betonen und zu verstärken“, da Fontane „beunruhigt“ gewesen sei wegen der Handlungsarmut des Romans. Peter Demetz, Formen des Realismus. Theodor Fontane. Kritische Untersuchungen, Literatur als Kunst (München: Hanser, 1964), 180.

117 Grundlegend für die Literaturgeografie und ihre Begrifflichkeiten ist Barbara Piatti, Die Geographie der Literatur. Schauplätze, Handlungsräume, Raumphantasien (Göttingen: Wallstein, 2008).

118 Vgl. dazu etwa Gerhart von Graevenitz, der dies eindrücklich an einigen Figuren belegt: „Der alte Stechlin war geteilt in Paradoxe, verdoppelt im alten Barby, Melusine geteilt in Fisch und Frau und verkehrt gespiegelt in ihrer Antipodin. Die Paare ließen aus zwei Hälften ganze Grotesken entstehen, Rex und Czako, die Prinzessin Ippe-Büchsenstein und ihr Oberförster, Nonne und Molchow, ,halb Eisklumpen, halb Bratapfel', ,Schnecken eben ,mit gehörnten Ochsenköpfen'“" Gerhart von Graevenitz, Theodor Fontane. Ängstliche Moderne. Über das Imaginäre (Konstanz: Konstanz University Press, 2014), 733. 
Komplexität der Handlung, der Vielzahl an Figuren und verhandelten Diskursen Herr zu werden.

Ausgehend von der semantischen Vieldeutigkeit des Namens Stechlin wird die ordnungsrelevante Funktion der Liebe zwischen Woldemar und Armgard in den Blick genommen. Darauf rückt der Komplex um Technik, Industrialisierung und die Soziale Frage ins Zentrum sowie die Ambivalenz der politischen Positionierungen. Anschließend werden narrative Strategien der Ordnungsherstellung auf formaler Ebene untersucht. Schließlich wird die Bedeutung der spezifischen "Gesinnung" in seiner Ambivalenz des Stechlin diskutiert sowie die Figurationen des Ausbruchs diskutiert.

\section{1 \\ Ambivalenz der Namensgebung. Die vielen „Stechline“}

Das Ordnungsprogramm des Romans Der Stechlin wird bereits auf den ersten Seiten entworfen. In der Ordnung des Raums, der in typisch realistischer Manier als zusammenhängende Topografie geschildert wird, findet dessen ungeachtet eine Proliferation der Semantik statt. Wie durch ein Zoomobjektiv wird eine "Seeenkette" anvisiert und schließlich auf einen See fokussiert den See Stechlin: „Das ist der Stechlin, der See Stechlin.“ (DS 7, Hervorhebung i..$^{119}$ ) Mit dieser Präzisierung, dem gesperrt gedruckten See, wird deutlich gemacht, dass der Begriff keineswegs so eindeutig ist, wie er zu sein scheint. Die Differenzierung erzeugt eine Ambivalenz, was die Bedeutungen des Namens Stechlin angeht und gibt gleichzeitig Ursache zu weiteren Präzisierungen. Der selbstauferlegte Zwang zum Ordnen der verschiedenen Träger desselben Namens ist die treibende Kraft des Anfangs und der Anstoß der Textbewegung.

Aber nicht nur der See führt diesen Namen, auch der Wald, der ihn umschließt. Und Stechlin heißt ebenso das langgestreckte Dorf, das sich, den Windungen des Sees folgend, um seine Südspitze herumzieht. (DS 7)

In Vogelflugperspektive wird nun das Dorf präsentiert, das eine schmale Gasse prägt, die bis zum Ausgang des Dorfes und darüber hinaus zu einer Brücke führt, die zu einem Herrenhaus, dem "Stechlin, Schloß Stechlin“ (DS 8, Hervorhebung i. O.), leitet. Neben dem Schloss trägt auch dessen Bewohner und Besitzer diesen Namen: „Und wie denn alles hier herum den Namen Stechlin führte, so natürlich auch der Schloßherr selbst. Auch er war ein Stechlin." (DS 9, Hervorhebung i. O.) Später wird auch der Sohn des Schlossherrn Dubslav von

119 Im Original wird Sperrdruck verwendet, der hier kursiv wiedergegeben wird. 
Stechlin, Woldemar, Stechlin genannt. ${ }^{120}$ Nicht zuletzt bezeichnet der Name auch das Buch, den Roman selbst. Der Name Stechlin wird polysemantisch aufgefächert und auf verschiedene Objekte auf mehreren Ebenen angewandt. ${ }^{121}$

Die Differenzierung der Namensgebung und -bedeutung hat eine doppelte Funktion. Zum einen werden durch Exklusion klar umrissene Identitäten, Gegenstände und Toponyme etabliert und voneinander abgegrenzt. Zum anderen entsteht durch die Polyvalenz eine Ambivalenz in der Referenz des Signifikanten auf das Signifikat. Die semantische Vieldeutigkeit des Namens wirkt gleichzeitig vereinend und differenzierend. Indem der Roman diese Bedeutungsvielfalt deutlich macht, zeigt sich gleich zu Beginn, dass es um mehr geht, als nur um die Figur Dubslav von Stechlin, den Adel oder eine Liebesgeschichte. Vielmehr steht ein ganzes Ordnungssystem auf dem Spiel, wie es in den vielinterpretierten Schlussworten von Melusine mitschwingt, die im präzisen Bezug zum Beginn stehen: „[E]s ist nicht nötig, daß die Stechline weiterleben, aber es lebe der Stechlin." (DS 387 , Hervorhebung i. O.) ${ }^{122}$

Dieses affirmierte Ordnungssystem ist komplex. Es besteht, wie zu sehen sein wird, aus Politik, Herrschaftsverhältnissen, der richtigen Gesinnung, der Kirche, topografischen Elementen und der Verbindung des Systems mit der Welt im "Globalisierungssymbol“123 des Sees Stechlin. Die Kohäsion dieser Ordnung kann nur mit ambivalenten und mehrdeutigen Bezügen sichergestellt werden, die in der Vieldeutigkeit des Namens Stechlin ihr Zentrum haben. ${ }^{124}$

120 So zum Beispiel in einem Gespräch der Freunde Rex und Czako (DS 199), ohne dies in der ausführlichen Art des Romananfangs zu kommentieren.

121 Peter James Bowman baut seine Lektüre darauf auf, dass er nur zwei Signifikate von Stechlin anerkennt: „There is, then, a deep kinship between the two Stechlins, the lake and the man. For the interrelatedness represented by the lake and the Gesinnung embodied by Dubslav are complementary." Peter James Bowman, „Fontane's ,Der Stechlin'. A Fragile Utopia“, The Modern Language Review 97, Nr. 4 (2002): 881. Hervorhebung i. O. Dagegen betont Liselotte Grevel die „Bedeutungserweiterung [...] im Bereich der Eigennamen“. Liselotte Grevel, „Das Alte und das Neue. Ambivalenz und Eindeutigkeit in Theodor Fontanes Roman ,Der Stechlin“', Zeitschrift für deutsche Philologie 127, Nr. 4 (2008): 518. Charlotte Jolles nennt es „[e]ine fünffältige Einheit: See, Wald, Dorf, Schloß und Schloßherr.“ Jolles, „,Der Stechlin'. Fontanes Zaubersee“, 246.

122 Das gesperrt gedruckte „der Stechlin“ ist zusätzlich abgesetzt und zentriert gedruckt.

123 Rolf Parr, „Kongobecken, Lombok und der Chinese im Hause Briest. Das ,Wissen um die Kolonien " und das ,Wissen aus den Kolonien' bei Theodor Fontane“, in Fontane und die Fremde, Fontane und Europa, hg. von Konrad Ehlich (Würzburg: Königshausen \& Neumann, 2002), 216.

124 In der Forschungsliteratur zum Stechlin ist die Frage der textimmanenten Struktur immer wieder Thema. Frühe Arbeiten betonen die Formlosigkeit des Romans und interpretieren diese als Ausdruck von Fontanes zunehmender Altersschwachheit. So etwa Conrad Wandrey: „Nun [nach Effi Briest] folgt der rasche Abstieg, der schnelle Verfall. [...] Der Stechlin zeigt ein deutliches Ermatten, ein Wissen beinahe um das Ende auch 
Schon in dieser Anfangssequenz wird die Technik entfaltet, mittels einer sich zunehmend weiter entwickelnden Differenzierung eine Ordnung unter die Phänomene zu bringen, was zugleich eine wachsende Ambivalenz zeitigt. Die Präzisierung des Namens Stechlin folgt den Darstellungsnormen des poetischen Realismus und läuft als geordnetes Nacheinander kontrolliert ab. Die Komplexität und das Potenzial der Ambivalenz zeigen sich erst auf der Ebene der Semantik und der symbolischen Ordnung. In der Begrifflichkeit der Narratologie lässt sich formulieren, dass die story mit Unordnung zu kämpfen hat, der discourse jedoch sehr ordentlich vorgeht. Semiotisch gesprochen ist das Signifikat nicht deutlich, wohl aber der Signifikant.

Der Anfang des Stechlin versucht mittels Differenzierung die Mehrdeutigkeit in eine Ordnung zu bringen. Dies hat zwei gegensätzliche Wirkungen. Zum einen gelingt es der Erzählung durch das ordentliche Erzählverfahren, in dem eine Bedeutung nach der anderen erläutert und der Topografie entsprechend aneinandergereiht wird, sich souverän und ordentlich zu präsentieren: Die Erzählung hat die Bedeutungsvielfalt unter Kontrolle, vermag diese zu bändigen und eindeutig zu sein. Darin äußert sich die Textintention, für eine ganz bestimmte Ordnungsform Partei zu ergreifen. ${ }^{125}$ Dass die Kontrolle von

der dichterischen Aktivität."Wandrey, Theodor Fontane, 294. Peter Demetz vergleicht den Fontane des Stechlin mit einem „Zauberkünstler“ in seiner „Abschiedsvorstellung“, der „noch einmal spielen will“ oder „müde geworden“ ist. Demetz, Formen des Realismus, 183.

Dies obwohl Thomas Mann in seinem für die Rezeption Fontanes sehr einflussreichen Essay Der alte Fontane schon 1910 dessen Alterswerk als sein eigentliches Werk herausarbeitete. Vgl.: Mann, „Der alte Fontane“. Siehe FN 105, S. 39f. oben.

Die Frage nach der scheinbaren Strukturlosigkeit nimmt auch Eric Miller zum Ansatzpunkt seiner Studie zum Stechlin: „Kein Versuch, den Stechlin zu bewerten, kommt darum herum, daß Fontanes Altersroman keine augenfällige Struktur aufweist. In der Handlung ist sie jedenfalls nicht zu finden, und daraus haben viele den Schluß gezogen, er besitze gar keine Struktur und stelle einen Verfall der Schaffenskräfte dar." Eric Miller, „Der Stechlinsee: Symbol und Struktur in Fontanes Altersroman“, The Journal of English and Germanic Philology 97, Nr. 3 (1998): 352. Die Struktur findet Miller schließlich in der bereits zitierten Beschreibung des Romans von Fontane als „Idee, die sich einkleidet“, die in der engen Verwebung der vier Leitmotive Glas, Rot/Feuer, Wasser und Mauer verstärkt werde: „Die vier Leitmotive durchdringen aber jeden Teil des Romans und erweitern und vertiefen so das Gewebe der eingekleideten Idee. [...] Alle vier Leitmotive sind im SeeSymbol verankert." Miller, 367 .

125 Bowman ist der Ansicht, dass Intention und Mittel im Stechlin sich widersprechen. Einem ähnlichen Ansatz wie dem der hier vorliegenden Studie zugrunde liegenden folgend, wenn auch mehr auf die rhetorischen als narrativen Verfahren bezogen, formuliert Bowman: „The novel not only reveals a ,großer Zusammenhang der Dinge', but also expounds and justifies this idea. It shows, but it also tells. Its inherent contradiction is that it is a monolithic and closed presentation of an idea of interrelatedness and openness. [...] It is as if the threat to open-endedness can only be avoided by an authorial fiat which 
Ambivalenz eines der zentralen Themen des Stechlin ist, wird ganz zu Beginn programmatisch entfaltet. Zum anderen geschieht durch diese Differenzierung genau das Gegenteil und unkontrollierte Ambivalenz wird erzeugt, die, um im Bildlichen des Stechlin zu bleiben, unter der glatten Oberfläche des Sees verborgen bleibt, jedoch jederzeit hervorbrechen kann. Dass die Erzählung selbst auf Ambivalenz angewiesen ist, um den narrativen Fortlauf im Sinn einer fortschreitenden Klärung und Differenzierung gewährleisten zu können, bleibt unter dieser Oberfläche verdeckt. ${ }^{126}$ Es wird nirgends deutlicher als in der Sprache selbst, dass die Ambivalenz mit der Ordnungsarbeit einhergeht, dass sie „Zwillinge“127 sind, wie Bauman formulierte. Sobald die Erzählung anhebt, erzeugt sie im Versuch, das zu Erzählende zu ordnen, Ambivalenzen, deren Klärung wiederum Antrieb für weiterführende Klärungen ist. Es sind dies die semantischen und narrativen Grundbewegungen des Textes, die im Folgenden an verschiedenen Themenkomplexen erläutert und präzisiert werden.

\subsection{Evidenz durch Narration. Die Liebe als Stütze der Ordnung}

Mit welchen narrativen Verfahren im Stechlin Evidenz generiert und eine bestimmte Ordnung etabliert wird, lässt sich besonders gut an der Liebesgeschichte von Woldemar und Armgard beobachten. ${ }^{128}$ Auf das Genre

is anything but open-ended, as if the clear espousal of the idea of a free exchange of diverse discourses makes it impossible to represent the functioning of that exchange." Bowman, „Fontane's ,Der Stechlin““, 886.

126 Vgl. zur Bedeutung der Oberfläche im Stechlin Graevenitz, Theodor Fontane, 705-740. Siehe Kap. 2.7 Der Ausbruch - kontrollierte Ambivalenz?, S. 8off. unten.

127 Bauman, Moderne und Ambivalenz, 17.

128 Zur Funktion der Liebe im Werk Fontanes, besonders im Stechlin, vgl. Anke Kramer, „Der große Zusammenhang der Dinge'. Zur Funktion des Eros in Fontanes ,Der Stechlin“, in Eros. Zur Ästhetisierung eines (neu)platonischen Philosophems in Neuzeit und Moderne, hg. von Maria Moog-Grünewald (Heidelberg: Winter, 20o6), 181-192. Sie zeigt, wie die Liebe die Figur zum einen durch „Negation ihres Begehrens erfolgreich der bürgerlichen Ordnung eingliedern“ kann und wie sie zum anderen dazu führt, „die Gesetze der Ordnung“ zu überschreiten. Kramer, 182. Für den Stechlin vertritt sie die These, dass der Eros als Gesprächsthema den Zusammenhang der Dinge garantieren kann: „Die Figuren benennen die Liebe [...] mehrmals als Möglichkeit der Überwindung des Ordnungsverlustes in der Welt.“ Kramer, 186. Und: „Eros fungiert als Gesprächskitt für gefährdete Gespräche; er erscheint in Der Stechlin geradezu als Voraussetzung für das Vermögen, einen Zusammenhang im Gespräch herzustellen [...]. Obgleich auf der Handlungsebene praktisch nicht vorhanden, kommt dem Begehren in Der Stechlin also eine wichtige Funktion zu: Gespräche hervorzutreiben und aufrechtzuerhalten. Das ist in diesem Roman von zentraler Bedeutung." Kramer, 190. 
Liebesgeschichte muss dabei mit Vorsicht Bezug genommen werden, wird doch gerade nicht erzählt, wie und warum diese beiden zueinander finden.

Die Ehe ist ein Brennpunkt der Spannung von Ambivalenz und Ordnung. Die Heirat hat die Funktion, die Kontingenz der Partnersuche in der Eindeutigkeit einer vertraglichen Regelung aufzuheben. In Theodor Fontanes Romanen wird dieses reziproke Verhältnis von Ambivalenz und Ordnung in der Institution der Ehe vielfach modelliert. Etwa in Effi Briest (1896), wo die Ehe als rechtliches Instrument der Ordnung eine neue Form der Ambivalenz in Effis Liebschaft zu Major von Crampas erst erzeugt, auch wenn ihre Funktion die wäre, solche Ambivalenz zu verhindern. Ein anderes Beispiel findet sich im Roman Frau Jenny Treibel (1892/1893), wo die Eheschließung zwischen Corinna und Marcell, ähnlich wie im Stechlin, lange subtil vorgezeichnet und vordergründig in Ambivalenz gehalten wird, so dass es letztlich zu einer Bestätigung der geltenden Ordnung kommt.

In Bezug auf die Liebesgeschichte Woldemars gibt es im Stechlin unterschiedliche Signale. Sowohl Melusine als auch Armgard sind wählbare Kandidatinnen. Warum und wie sich Woldemar schließlich für Armgard entscheidet, wird weder erklärt noch gibt es eindeutige Szenen. Die beiden Schwestern repräsentieren gegensätzliche Positionen. Zwar werden sie als Rivalinnen dargestellt, deren Konkurrenz sich jedoch innerhalb klar definierter Grenzen äußert. Die Liebe ist im Stechlin ein simples, sachliches und nützliches Gefühl, welches die Ordnung - beispielsweise der Geschwisterliebe, des Patriarchats oder der Verwandtschaftsbeziehungen - nur insoweit gefährdet, als es nötig ist, das Erzählen voranzutreiben und die Kohäsion der Erzählung zu stärken. Erst wenn die Ebene der symbolischen Ordnung mitberücksichtigt wird, wird deutlich, warum sich Woldemar so entscheiden muss: Armgard steht als Figur für eine Fortführung des Bisherigen. Es ist in dieser Hinsicht also kein kontingenter Entscheid zwischen Armgard und Melusine, sondern ein ordnungstechnisch notwendiger, wie im Folgenden gezeigt wird. ${ }^{129}$

129 Auch Thomas Mann betont, dass die Entscheidung für Armgard zwingend ist: „Uns anderen aber sollte die Natürlichkeit, Angemessenheit und Notwendigkeit von Woldemars Entscheidung denn doch einleuchten.“ Mann, „Anzeige eines Fontane-Buches [1919]“, 272. Diese selbstverständliche Akzeptanz der Wahl, ihre scheinbare Notwendigkeit entspricht der Ordnungsabsicht, den Erfordernissen der symbolischen Ordnung, und wird nicht aus der Geschichte selbst entwickelt, in der Armgard und Melusine durchaus ebenbürtig sind. Durchaus passend zu Thomas Manns Argumentation der Selbstverständlichkeit ist auch, dass er bei der Erörterung der Frage nicht von Melusine, sondern von "der Ghiberti“ spricht. Melusine war mit Ghiberti verheiratet, ließ sich scheiden und lehnt nun diesen Nachnamen ab. Dagegen empfindet Wandrey die Wahl als „unmotiviert“. Wandrey, Theodor Fontane, 305 . 


\subsubsection{Die rauchende Melusine oder die heilige Armgard?}

Woldemar, der in Berlin im Regiment dient, ist regelmäßig im Haus der Barbys zu Besuch. Der Graf von Barby ist seit fünfzehn Jahren verwitwet und lebt mit seinen beiden Töchtern Melusine und Armgard in Berlin in einer Mietwohnung, die zwar dem Stand der Familie nicht ganz angemessen ist, die sie jedoch sehr schätzen. Die Information, dass Woldemar regelmäßig mit den Töchtern des Barby verkehrt, wird dem Leser über ein Gespräch zwischen den beiden Freunden Woldemars, Czako und Rex, vermittelt, die auf dem Weg zum Schloss Stechlin sind, um Woldemar zu besuchen, der sich bei seinem Vater Dubslav aufhält:

[Rex:] „Das bedeutet, daß in einem solchen Hause verkehren und sich mit einer Tochter verloben so ziemlich ein und dasselbe ist. Bloß eine Frage der Zeit. [...] Unser Woldemar wird sich aber mittlerweile vor ganz andre Schwierigkeiten gestellt sehen."

[Czako:] „Und die wären? Ist er nicht vornehm genug? Oder mankiert vielleicht Gegenliebe?“

„Nein, Czako, von ,mankierender Gegenliebe', wie Sie sich auszudrücken belieben, kann keine Rede sein. Die Schwierigkeiten liegen in was anderm. Es sind da nämlich, wie ich mir schon anzudeuten erlaubte, zwei Comtessen im Hause.“ (DS 101f.)

In diesem Dialog werden die Schwestern als ebenbürtige Rivalinnen charakterisiert. Eine davon wird Woldemar heiraten, davon sind Rex und Czako überzeugt. Welche es jedoch ist, bleibt in den Augen der beiden offen. Sie beurteilen die Lage gegensätzlich: Rex tippt auf Armgard, „schon weil sie eben die jüngere ist“, aber „so ganz sicher ist es doch keineswegs.“ (DS 102) Wenn man den Stechlin als Ordnungsroman liest, lassen sich bessere Gründe als bloß der Altersunterschied finden, die in dieser impliziten Symbolpolitik zur Stützung der Ordnung ausschlaggebend sind. ${ }^{130}$

130 Vgl. dazu auch die symbolisch aufgeladene Darstellung der zwei Figuren: „Die brennende Frage, ob er nun Armgard oder Melusine heiraten wird, ist symbolisch schon im die Berlinkapitel einleitenden Gespräch der Schwestern geklärt. Während Armgard nämlich lieber in den häuslichen Kamin blickt, betrachtet Melusine vom Balkon aus die im Hinblick auf den Romanverlauf symbolisch untergehende Sonne.“ Andreas Amberg, „Poetik des Wassers. Theodor Fontanes ,Stechlin'. Zur protagonistischen Funktion des SeeSymbols“, Zeitschrift für deutsche Philologie 115, Nr. 4 (1996): 554. Diese Symbolik ist sicherlich zutreffend, jedoch erklärt dies nicht, warum der nach innen gerichteten Symbolik der Vorzug gegeben wird. Um dies zu erklären, ist es nötig, auf die Ordnung des Romans und die Positionierung der Figuren in Bezug auf diese einzugehen. 
Es zeigt sich, dass die jüngere Armgard zu den brennenden aktuellen Fragen wie Geschlechterrollen, Politik und Technik im Gegensatz zu Melusine keine Stellung bezieht. Damit entspricht sie einem konservativen Rollenverständnis. Indirekt wird dies in einer Szene thematisiert, in der Adelheid, Dubslavs Schwester und Oberin im Kloster Wutz, die ihren Bruder finanziell immer wieder unterstützt, als verstockte Witzfigur überzeichnet ist und Melusine diffamiert:

[Adelheid:] „Und ich verwette mich, diese Melusine raucht auch.“

[Dubslav:] „Ja, warum soll sie nicht? Du schlachtest Gänse. Warum soll Melusine nicht rauchen?"

„Weil Rauchen männlich ist."

„Und schlachten weiblich ... Ach, Adelheid, wir können uns über so was nicht einigen. Ich gelte schon für leidlich altmodisch, aber du, du bist ja geradezu petrefakt." (DS 276)

Adelheid argumentiert im Sinn einer alten Ordnung, in der die Frau vor allem die Funktion der Repräsentation einnahm und sich nur in einem engen Rahmen des Sittsamen bewegen durfte. Dubslav nimmt ihre Position belustigt auf und entlarvt durch seinen absurden Vergleich mit der Schlachtung Adelheids Haltung als künstlich und überkommen. Dadurch wird die eigentlich als zielführend gedachte Bewertung Adelheids wiederum ambivalent: Ihre Aussage befeuert die Rivalität der Schwestern weiter, indem ihre Ansicht Signale in beide Richtungen, für Armgard wie für Melusine, aussendet. ${ }^{131}$

Dubslavs Haltung wird in dieser Szene deutlich von derjenigen Adelheids abgegrenzt und damit klar gemacht, dass er, der durchaus auf der Seite der Konservativen steht, nichts mit den altmodischen Ordnungsvorstellungen einer Adelheid zu tun hat. Daraus resultiert für Dubslav ein positiver Distinktionsgewinn in Bezug auf Sympathie, Zuverlässigkeit und Vertrauenswürdigkeit. ${ }^{132}$

131 In solchen Szenen zeigt sich, dass es im Roman tatsächlich auf die „Mache“ ankommt, wie Fontane die Form seines Romans im schon zitierten Briefentwurf an Adolf Hoffmann nennt. Dubslav selbst resümiert an einer Stelle: „Wohl entsann er [Dubslav] sich, in eigenster Person [...] gelegentlich sehr ähnliches gesagt zu haben. Aber doch immer nur scherzhaft. Und wenn zwei dasselbe thun, so ist es nicht mehr dasselbe." (DS 323) Vgl. dazu auch Bowman: „He [Dubslav] judges a statement less by its content than by the way it is expressed.“ Bowman, „Fontane's ,Der Stechlin“', 880.

132 Das große Figurenarsenal im Stechlin lässt sich grundsätzlich in drei Gruppen einteilen neben einer Gruppe der unwichtigen Statisten in positiv besetzte Figuren, die sich durch ihre Offenheit und tendenziell selbstironische Qualität auszeichnen und negativ besetzte biedere, geradezu grotesk gezeichnete Figuren. Vgl. Demetz, Formen des Realismus, $186 \mathrm{f}$.

Adelheid von Stechlin ist unter diesen engstirnigen Figuren die einzige wichtige Person. „Diese Figur verkörpert gerade nicht den Wandel, sondern die Konsistenz und 
Schwerer als das unterstellte Rauchen wiegen jedoch vor dem Hintergrund des Ordnungsdiskurses Melusines emanzipiertes, da dem männlichen Geschlecht ebenbürtiges Verhalten in philosophischen Gesprächen. ${ }^{133}$ Ihre Begeisterung für die moderne Technik, für „Torpedoboote, Tunnel unter dem Meere, Luftballons" (DS 148), ihr Glaube an den technischen Fortschritt und damit die kommenden „Luftschifferschlachten“ (DS 148) disqualifizieren sie nach traditionellem Rollenverständnis. ${ }^{134}$ Armgard dagegen hält sich klar an die Rollenbilder der bescheidenen, häuslichen Frau, wie sich in einem Gespräch zwischen Woldemar, Melusine und Armgard über weibliche Vorbilder deutlich zeigt. Woldemar, der eben aus England zurückgekehrt ist, ist bei den Barbys zu Besuch und schwärmt von der „Kapelle Heinrich des Siebten“, wo ihm die Särge der Königin Elisabeth von England und Maria Stuart den „denkbar großartigsten“ Eindruck machten:

Das Gefühl: ,zwischen diesen beiden Gegensätzen pendelt die Weltgeschichte. Zunächst freilich scheinen wir da nur den Gegensatz zwischen Katholizismus und Protestantismus zu haben, aber weit darüber hinaus (weil nicht an Ort und Zeit gebunden) haben wir bei tiefergehender Betrachtung den Gegensatz von Leidenschaft und Berechnung, von Schönheit und Klugheit. (DS 238)

Mit dieser Aussage Woldemars wird dem Leser nahegelegt, Melusine und Armgard diesen Frauentypen zuzuordnen. Melusine jedoch scheint die scheinbaren Gegensätze in sich zu vereinigen, wie ihre mythologische Figur in der Sage

die vergebliche, wenn auch umso energischere Abwehr von Kontingenz [...]. Für Adelheid sind Name, Ort, Stand und Geschichte eines. Sie ist erfüllt von einem festen Begriff des Stechlin, den sie mit Hilfe eines ausgefeilten Systems von Ein- und Ausschlüssen zu stabilisieren sucht; es ist ein selbstidentisches Konzept dessen, was ,Stechlin“ bedeuten kann.“ Barbara Naumann, „Schwatzhaftigkeit. Formen der Rede in späten Romanen Fontanes", in Theodor Fontane. Am Ende des Jahrhunderts, hg. von Hanna Delf von Wolzogen, Bd. 2: Sprache, Ich, Roman, Frau, 3 Bde. (Würzburg: Königshausen \& Neumann, 2000), 21.

Jedoch ist Adelheid machtlos, wie alle diese Figuren: „Closed minds and intolerant attitudes appear marginal and harmless in Der Stechlin.“ Bowman, „Fontane's ,Der Stechlin“', 883. Und gerade diese Harmlosigkeit, die scheinbare Idylle, diese realistische Behaglichkeit äußert sich in ihrer Explizitheit als künstliche narrative Inszenierung.

133 So etwa im den Roman beschließenden Gespräch mit Pastor Lorenzen.

134 Luftschiffe als Symbol des Elements Luft gehören, zusammen mit den Torpedobooten und dem Feuerwerk als weiteren Naturelementen, zu den typischen "Nixenattribute[n]“ der Melusine. Renate Böschenstein, „Fontanes Melusine-Motiv“, in Verborgene Facetten. Studien zu Fontane, hg. von Hanna Delf von Wolzogen und Hubertus Fischer (Würzburg: Königshausen \& Neumann, 2006), 51. Vgl. auch Bettina Plett, „Frauenbilder, Männerperspektiven und die fragwürdige Moral. Applikation und Demontage von Rollenbildern und Wertzuschreibungen in Fontanes Romanen“, Fontane-Blätter, Nr. 68 (1999): 118-129. 
Mensch und Fisch vereinigt. Bei ihr sind „Leidenschaft und Berechnung, [...] Schönheit und Klugheit" offensichtlich keine sich ausschließenden Attribute, wird sie doch als leidenschaftlich, aber eben auch den technischen Dingen, der Berechnung und Klugheit zugeneigt, geschildert. Armgard dagegen bringt eine dritte historische Frauenfigur ins Spiel, der sie sich verbunden fühlt: Elisabeth von Thüringen, die von 1207 bis 1231 lebte und als eine Heilige der katholischen wie der protestantischen Kirche für tätige Nächstenliebe steht. Ihr Ziel sei es, sagt Armgard, „Andern leben und der Armut das Brot geben - darin allein ruht das Glück. Ich möchte, daß ich mir das erringen könnte. Aber man erringt sich nichts. Alles ist Gnade." (DS 239, Hervorhebung i. O.)

Diese Aussage qualifiziert Armgard in den Augen Melusines als "Kind“ (DS 239). ${ }^{135}$ Als solches ist Armgard als die künftige Frau Woldemars dazu prädestiniert, eine ausgleichende Haltung einzunehmen. In der Metaposition der Heiligen ist es ihr um die harmonische Verschmelzung von konkreten und abstrakten Gegensätzen zu tun. So übernimmt sie dennoch eine wichtige Funktion in der Affirmation der (weltlichen) Macht, an der sie, gemäß dieser Rolle, kein Interesse hat.

Unmittelbar nach dieser Diskussion verabschiedet sich Woldemar, Armgard begleitet ihn hinaus. Kurz danach kündigt sie ihrer Schwester die Verlobung an. Es liegt nahe, Armgards Eintreten für Elisabeth von Thüringen als ausschlaggebend für die Entscheidung Woldemars zu ihren Gunsten zu betrachten. Durch ihre Position der Enthaltsamkeit in Politik und Weltlichem anerbietet sie sich als ideale Ehefrau Woldemars zur Stützung der bisherigen Ordnung. Melusine dagegen würde mit ihrem Selbstbewusstsein die konservative Ordnung provozieren. Was der alte Stechlin hervorragend kann - die Spannung mittels Ironie aushalten und diejenigen bei Laune halten, die ihm zwar zuwider, aber nützlich sind, wie Baruch und Isidor Hirschfeld, Adelheid oder Katzler -, kann die vergleichsweise undiplomatische Melusine nicht. Ihre Aufgeschlossenheit auch hinsichtlich der Sozialen Frage würde für Widerspruch und Disharmonie im Lager der Stechline und der Konservativen sorgen.

Neben diesen inhaltlich-charakterlichen Gründen - wie Klugheit, Temperament und Leidenschaft - ist es auch die Konzeption der Figur Melusine selbst, in der die Ambivalenz schon eingeschrieben ist. Dass sie geradezu in formaler Hinsicht ein Gegenpol der Ordnung ist, wird etwa an ihrem zweideutigen Zivilstand ersichtlich, von dem Rex Czako erzählt:

135 Die Figur der „Kindfrau“ ist bei Fontane insbesondere in Effi Briest zentral. Elemente davon finden sich jedoch auch im Stechlin, wie in dieser Beschreibung Armgards deutlich wird oder auch, später, in der Figur Agnes. 
„Denn auch die ältere [Melusine], wiewohl schon über dreißig, ist sehr reizend und zum Überfluß auch noch Witwe - das heißt eigentlich nicht Witwe, sondern richtiger eine gleich nach der Ehe geschiedene Frau. Sie war nur ein halbes Jahr verheiratet, oder vielleicht auch nicht verheiratet."

„Verheiratet, oder vielleicht auch nicht verheiratet,“ wiederholte Czako, während er unwillkürlich sein Pferd anhielt. „Aber Rex, das ist ja hoch pikant.“ (DS 102)

,Pikant' ist dies wegen der Scheidung und den möglichen Gründen für diese oder, wenn Melusine gar nicht verheiratet gewesen wäre, wegen ihres ehelosen Verhältnisses mit Ghiberti. ,Pikant' ist es auch, weil dieser ungeklärte Status eine Unentscheidbarkeit darstellt, die die geforderte Identität aufsprengt. Melusine wird als Figur gezeichnet, die wesenhaft ambivalent ist. Dieses Merkmal ist schon in ihrem Namen eingeschrieben: Als Mischwesen zwischen Frau und Fisch bricht Melusine Ordnungsprinzipien auf und wird als Personifikation von Ambivalenz im Setting des Romans greifbar. ${ }^{136}$

136 Die historischen Vorlagen zur Melusine-Sage werden aufgearbeitet in: Klaus Briegleb, „Fontanes Elementargeist: Die Preußin Melusine. Eine Vorstudie zum ,Stechlin“, in Theodor Fontane. Am Ende des Jahrhunderts, hg. von Hanna Delf von Wolzogen, Bd. 2: Sprache, Ich, Roman, Frau, 3 Bde. (Würzburg: Königshausen \& Neumann, 2000), 109-122.

Vgl. dazu auch Edda Ziegler, die ebenfalls die Ambivalenz der Melusine betont. Dabei argumentiert sie vornehmlich, dass Melusine eine Destabilisierung der Geschlechteridentitäten verkörpere: „Die tradierte Dichotomie von Geist und Natur, die sich festmacht an einem natur- und triebhaften, deshalb zugleich attraktiven und gefährlichen Bild des Weiblichen und seinem Gegenpol, dem sich durch Geist und Tat historisierenden männlichen Prinzip, wird durch Fontanes Melusinen ebenso verunsichert wie durch die Figur seiner nervösen halben Helden. Damit ist die bisher gültige Geschlechterordnung destabilisiert.“ Edda Ziegler, „Die Zukunft der Melusinen. Weiblichkeitskonstruktionen in Fontanes Spätwerk", in Theodor Fontane. Am Ende des Jahrhunderts, hg. von Hanna Delf von Wolzogen, Bd. 2: Sprache, Ich, Roman, Frau, 3 Bde. (Würzburg: Königshausen \& Neumann, 2000), 175. Und: „Melusine lebt eine luftige, freischwebende, aber eben auch nicht gesellschaftlich definierte Existenz." Ziegler, 179. Melusine könne aufgrund ihrer, wie Ziegler schreibt, Unfähigkeit, Frau und Mutter zu werden, auch nicht revolutionär im Sinn einer zukunftsgerichteten Veränderung sein. Als revolutionäre Figur bezeichnet sie die verhalten optimistische junge Agnes. „Damit aber wird das Revolutionäre an dieser Konzeption von Weiblichkeit, sofern revolutionär die radikale gesellschaftliche Veränderung meint, eher fragwürdig, nicht nur nach der Norm der preußischen Gesellschaft der Fontane-Zeit. [...] Melusines Leben ist rückwärts bezogen, zum einen durch die Bindung an die Väter, zum anderen durch ihre Vorliebe für die Mythenwelt des Stechlinsees. Denn dessen Verbindung zur bewegten Gegenwart, dem revolutionären Weltgeschehen, bleibt in der ereignislosen Statik des Mythischen aufgehoben. Indem Melusines Hang zum Revolutionären ahistorisch bleibt, ist sie nicht eigentlich revolutionär." Ziegler, 179. Mag diese Argumentation auch plausibel sein, so ist doch zu betonen, dass Melusine im Vergleich zu den anderen Figuren diejenige ist, die am meisten auf die Zukunft gerichtet ist, gerade auch mit ihrem Interesse an Technik. Auch 
Auch die als Liebesunfähigkeit apostrophierte Kinderlosigkeit gehört zum Repertoire der Sagenfigur Melusine, eine Eigenschaft, die wiederum eine zentrale Funktion der Ehefrau in diesem Ordnungssystem nicht erfüllt. Auf der story-Ebene gibt es Hinweise auf diese Liebesunfähigkeit, etwa in der Erzählung Melusines über eine Reise mit ihrem damaligen Ehemann Ghiberti. Sie schildert eine Szene in einem Eisenbahntunnel, wobei aus ihrer Erzählung nicht klar wird, ob es sich um eine Anspielung auf eine versuchte oder tatsächliche Vergewaltigung von Seiten Ghiberti handelt, dessen Unfähigkeit in Liebesdingen oder um die Asexualität Melusines. ${ }^{137}$

\subsection{2 „Im Stillen“vollzieht sich die Ordnung}

In Anbetracht der großen Bedeutung von Woldemars Entscheidung, die, wie oben argumentiert wurde, systemrelevant ist, erstaunt es, wie unbegründet sie ausfällt. In der geradezu offensiven Vorhandenheit dieser Leerstelle zeigt sich das Prekäre in der narrativen Ordnung des Stechlin. Die Künstlichkeit der Entscheidung wird im Nicht-Benennen sichtbar, die Verfahren werden in ihrer Unsichtbarkeit evident. Motiviert wird die Entscheidung durch die Notwendigkeit des Fortbestands der Ordnung. Es handelt sich um eine finale Motivierung, die in ausgesprochen wenig Mythologie eingekleidet ist. ${ }^{138}$

vermag sie durchaus Einfluss auf die anderen Figuren zu nehmen, wenn sie auch ihr Vermächtnis nicht in der Form von Kindern weitergibt. Was die Geschlechterrollen angeht, so ist ihre Position, bei aller Mythologie und gerade in Kontrast zu derjenigen Armgards, doch revolutionär.

Auch Isabel Nottinger betont das Modernistische in Melusine als Vorläuferin der Décadence-Frauenfiguren zwischen femme fatale und femme fragile. Isabel Nottinger, Fontanes Fin de Siècle: Motive der Dekadenz in "L'Adultera", „Cécile“ und "Der Stechlin" (Würzburg: Königshausen \& Neumann, 2003), 145-161.

137 Für Edda Ziegler ist es eindeutig, dass es sich um Liebesunfähigkeit Melusines handeln muss. Sie liest auch Melusines Reaktion auf die Bekanntgabe der Verlobung von Woldemar und Armgard - „Ich habe nur die Freude, du hast auch die Last.“ (DS 240) in dieser Hinsicht. Ziegler, „Die Zukunft der Melusinen“, $178 \mathrm{f}$. Mir scheint diese Lektüre konservativ und zu stark auf den mythologischen Kontext abgestützt zu sein. Auch ist diese Lesart blind gegenüber der Rivalität zwischen den Schwestern und verfällt so der scheinbaren Harmlosigkeit der Erzählung, übersieht die Fragilität des Idylls („a fragile utopia“ heißt es bei Bowman, „Fontane’s ,Der Stechlin““.).

Vgl. zur Tunnel-Episode auch den nicht ganz humorfreien Eintrag im Fontane- $A B C$, der allerdings ebenfalls nur die Variante Vergewaltigung und Asexualität aufbietet und daraus den Schluss zieht: „Künstliches Licht hilft hier nicht weiter.“ Stefan Neuhaus, Fontane-ABC, Reclam-Bibliothek 1631 (Leipzig: Reclam, 1998), 204. Die dritte Möglichkeit, dass Ghibertis Liebeskünste Melusine nicht zu befriedigen vermögen, und die ihr eine eigenständige Sexualität zuspricht, wird nicht diskutiert.

138 Vgl. dazu: „Die Handlung final motivierter Texte findet vor dem mythischen Sinnhorizont einer Welt statt, die von einer numinosen Instanz beherrscht wird." Martinez und Scheffel, 
Insofern ist die Zusammenführung von Armgard und Woldemar eine unverschleierte Wirkung der Ordnung.

In einem weiteren Gespräch mit Czako spielt Rex auf die Art und Weise der Entscheidungsfindung Woldemars an. Die beiden sind auf dem Rückweg vom Haus der Barbys und sprechen über Woldemar und die zwei Schwestern. Czako sagt:

„Viel Vertrauen zu Freund Woldemars richtigem Frauenverständnis hab’ ich eigentlich nicht, aber ich sage trotzdem: Melusine.“

[Rex:] „Und ich sage: Armgard. Und Sie sagen es im Stillen auch.“ (DS 201)

Der biedere Rex behält Recht gegenüber dem frivolen Sprücheklopfer Czako. Letzterer ist auch, als Zugezogener mit einer Herkunft im Osten, mit dem Habitus der Stechlins weniger vertraut als Rex, der in diesen Kreisen aufgewachsen ist und deshalb ein Gespür für den Vollzug der Ordnung hat. Dieser Vollzug der Ordnung schlägt sich in der Narration nieder. Deshalb fällt die Entscheidung „im Stillen“, wirkt im Hintergrund und muss gar nicht ausgesprochen werden. Rex nimmt es vorweg: Die diskursive Macht der Ordnungsprinzipien wirkt „im Stillen“.

Dabei zeigt sich eine weitere Funktion der Liebesgeschichte: Die immer wieder aufgenommenen Diskussionen der Figuren darüber, welche der Schwestern Woldemar heiraten wird, sorgen dafür, dass die Ambivalenz aktuell bleibt und die Geschichte nicht an Kohäsion und Fortschritt verliert. Die pointiert gesetzten Hinweise erzeugen Spannung und verschieben das Gewicht jeweils auf Melusines oder Armgards Seite. Gleichzeitig wird mit jedem Hinweis in die eine oder andere Richtung auch das Gegenteil gesagt: Das Ungesagte läuft mit. Schließlich lässt sich obige Stellungnahme von Rex auch als falsche Fährte lesen, wie die Tatsache, dass Woldemar mehr mit Melusine spricht und schäkert als mit Armgard. Auch die oben diskutierte Unterstellung Adelheids, Melusine rauche und disqualifiziere sich dadurch, wird durch den Umstand, dass dies von der lächerlich altmodischen Adelheid gesagt wird, gegen die Intention derselben, zu einem Argument für Melusine.

Um Spannung zu erzeugen, muss die ambivalente Bewertung der Figuren, mithin die Kontingenz der Wahl, kontrolliert und in wenigen Unterschieden gleichsam konzentriert werden. Es darf, bildlich gesprochen, nur eine schmale Lücke in der Ordnung, die ansonsten geschlossen ist, offen bleiben. Im Stechlin

Einführung in die Erzähltheorie, 111. Der mythische Sinnhorizont des Stechlin bildet ebenjene Ordnung. Ihr Geltungsbereich ist nicht so unbedingt, wie dies bei herkömmlich final motivierten Texten der Fall ist, sondern wird im Stechlin kritisch hinterfragt. 
wird dies präzise vorgeführt. ${ }^{139}$ Es gibt keinen Zweifel daran, dass sich die Schwestern nicht zerstreiten, dass nicht plötzlich eine dritte Kandidatin auftreten oder Woldemar sich gegen Dubslav auflehnen könnte. Diese Möglichkeiten sind in der Erzählordnung des Stechlin, durchaus in Bezug auf die dem Realismus verpflichteten Begrenzungen, unausgesprochen ausgeschlossen. Durch den kleinen Riss - die Spannung hinsichtlich Woldemars Wahl als eine kontrollierte Unsicherheit - wird diese Ordnung wiederum als notwendig bestätigt.

Während des Besuchs Woldemars bei den Barbys, bei dem es zur Verlobung kommt, heißt es unvermittelt nach dem Gespräch über Elisabeth von England, Maria Stuart und Elisabeth von Thüringen:

Stechlin ging. Armgard gab ihm das Geleit bis auf den Korridor. Es war eine Verlegenheit zwischen beiden, und Woldemar fühlte, daß er etwas sagen müsse. "Welche liebenswürdige Schwester Sie haben."

Armgard errötete. „Sie werden mich eifersüchtig machen.“

„Wirklich, Comtesse?"

„Vielleicht ... Gute Nacht.“

Eine halbe Stunde später saß Melusine neben dem Bett der Schwester und beide plauderten noch. Aber Armgard war einsylbig, und Melusine bemerkte wohl, daß die Schwester etwas auf dem Herzen habe.

„Was hast du, Armgard? Du bist so zerstreut, so wie abwesend.“

"Ich weiß es nicht. Aber ich glaube fast ..."

"Nun was?"

„Ich glaube fast, ich bin verlobt.“ (DS 239)

Die Entscheidung kommt, weniger für Melusine als für den Leser, überraschend. Im Vorfeld der Szene gab es keinerlei Entwicklung, keine $\mathrm{Zu}$ spitzung, die darauf hindeutete. Hinzu kommt, dass die eigentliche Szene des Verlobung-Versprechens nicht nur ausgespart wird, selbst eine Leerstelle, in der dieses Versprechen hätte gegeben werden können, fehlt.

Die drei Punkte, die eine Aussparung anzeigen, stehen im Zitat stets innerhalb der Anführungs- und Schlusszeichen der direkten Rede. Sie signalisieren deutlich Sprechpausen und Verlegenheit, zeigen jedoch nicht an, dass etwas stattfindet, was nicht erzählt wird; es ist also nicht von einer Pause im Sinn

139 Ein gänzlich geschlossenes System wäre mit Jurij Lotman ein „sujetloser Text“. Jurij M. Lotman, Die Struktur literarischer Texte, übers. von Rolf D. Keil, 4. Aufl. (Paderborn: Wilhelm Fink, 1993), 340. 
Genettes auszugehen, wo nur der discourse suspendiert ist, die Handlung jedoch weiterläuft. Die Konversation zwischen Armgard und Woldemar wird mit der Verabschiedung abgeschlossen und ist darum eigentlich vollständig. Woldemars Antrag hätte also nach Armgards letztem Satz „Vielleicht ... Gute Nacht." geschehen müssen, wo - nach der Verabschiedung - eigentlich kein Platz mehr ist. Ganz explizit wird die Verlobung hier „im Stillen“ vollzogen.

Das an dieses Gespräch anschließende „Sechsundzwanzigste Kapitel“ löst mit den ersten Sätzen das unausgesprochene Versprechen der Erzählung ein, dass durch die zukünftige Ehe keine neue Unordnung gestiftet werden wird. Die Spannung zwischen den Schwestern, die bis anhin für den Fortgang der Erzählung bedeutsam war, wird aufgelöst:

Und was die jüngere Schwester der älteren zugeflüstert hatte, das wurde wahr und schon wenige Tage nach diesem ersten Wiedersehn waren Armgard und Woldemar Verlobte. Der alte Graf sah einen Wunsch erfüllt, den er seit lange gehegt und Melusine küßte die Schwester mit einer Herzlichkeit, als ob sie selber die Glückliche wäre.

„Du gönnst ihn mir doch?“

"Ach, meine liebe Armgard,“ sagte Melusine, „wenn du wüßtest! Ich habe nur die Freude, du hast auch die Last.“ (DS 240)

Hier werden sorgsam potenzielle Konflikte aus dem Weg geräumt. Die Erzählung gibt Garantien dafür ab, dass alles weiterhin im Rahmen der Ordnung verläuft, dass dieser Handlungsstrang nun beendet ist und der Riss, den die Überwindung der Ambivalenz in der Wahl zwischen Armgard und Melusine in die Oberfläche gezogen hat, geschlossen wird. Die Funktion des Vorantreibens von Handlung wird von einer anderen, ebenfalls klar eingegrenzten Ambivalenz übernommen.

Die frühere Rivalität zwischen den beiden wird explizit thematisiert und nachträglich bestätigt. Indem sich Armgard vergewissert, dass Melusine ihr Woldemar ,gönne', wird umso naheliegender, dass diese ebenfalls Interesse an ihm hatte, was wiederum die unausgesprochene Konkurrenz zwischen den beiden bestätigt. Dass es so etwas wie Neid zwischen den Schwestern geben könnte, wird ebenso verschwiegen, wie der Sachverhalt, dass Melusine als Dreißigjährige noch immer keinen Mann hat und als ungebundene Frau der Norm widerspricht und so wiederum ein Herd potenzieller Unruhe darstellt. ${ }^{140}$

140 Dass es tatsächlich ein Problem für die Norm darstellt, dass Melusine unverheiratet ist, zeigt sich in folgendem Dialog zwischen dem Grafen Barby und dessen Diener Jeserich: ",Ja, Jeserich, du willst nicht 'raus mit der Sprache. Das hilft dir aber nichts. Wie denkst du dir die Sache?' Jeserich schmunzelte, schwieg aber weiter, weshalb dem alten Grafen nichts übrig blieb, als seinerseits fortzufahren. ,Natürlich paßt Armgard besser, weil sie 
Während Agnes in ein Heim gesteckt und so vom Stechlin verbannt und neutralisiert werden kann, bleibt Melusine mit ihrem Prinzip des Zweifels und ihrer inheränten Ambivalenz stets präsent.

\subsubsection{Narrative Funktionen der Liebesgeschichte}

Mit der Heirat von Woldemar und Armgard wird die alte Ordnung konserviert. Das Idyll wird fest- und fortgeschrieben, dessen Fragilität weiterhin übersehen. In dieser Hinsicht veranschaulicht die Überführung der anfänglichen Ambivalenz zwischen Melusine und Armgard in die Ordnung der Ehe die Macht der Erzählung, Ordnung herzustellen. Es ist ein zirkulärer Prozess, in dem Ambivalenz zum Zweck ihrer Auflösung inszeniert wird. Dieses Verfahren ist jedoch zweischneidig, da dadurch auch die Konstruktion der Ordnung zu Tage tritt. ${ }^{141}$

Der Text inszeniert also Ambivalenz auf der discourse-Ebene und damit verbunden die Kontingenz auf der story-Ebene, um seine Kontrollmechanismen unter Beweis zu stellen. ${ }^{142}$ Anders als bei der Polysemantik des Namens Stechlin zu Beginn des Romans, wo der Ambivalenz durch ausgreifende strukturierte Spezifizierung der Namensbedeutungen begegnet wird, ist es im Falle von Melusine und Armgard die Narration selbst, die Evidenz herstellt. Die Ambivalenz wird nicht aufgelöst, indem Unterscheidungen vorgenommen werden - dies wäre der Fall, wenn etwa die Vorteile und Nachteile der Schwestern erörtert würden -, sondern „im Stillen“ der Evidenz der Ordnung.

Die Frage jedoch bleibt bestehen, ob jene Ordnung mit den angewandten Mitteln in einer Zeit der Veränderung bewahrt werden kann. Deutlich stellt sich diese Frage insbesondere bei den narrativen Konfliktvermeidungsstrategien; diese lässt sich auch als Ignoranz gegenüber Problemen personeller wie

jung ist; es ist so mehr das richtige Verhältnis, und überhaupt, Armgard ist sozusagen dran. Aber, weiß der Teufel, Melusine ...',Freilich, Herr Graf." (DS 112)

141 Damit sind deutliche Analogien zu Paul de Mans Metapherntheorie in der Untersuchung von Marcel Prousts À la recherche du temps perdu zu sehen. De Man zeigt, wie Proust seine Priorisierung der Metapher über die Metonymie mittels einer solchen begründet. Vgl. Paul de Man, „Semiologie und Rhetorik“, in Allegorien des Lesens, übers. von Werner Hamacher und Peter Krumme (Frankfurt am Main: Suhrkamp, 1988), 43-45. Im Stechlin wird die Ambivalenz dazu verwendet, die Ordnung zu stützen.

142 So kann Bowman auch schreiben, dass Dubslav von Stechlin über ein idealisiertes Umfeld verfüge: „Like Dubslav himself, the environment he inhabits is less real than ideal. Fontane states that Der Stechlin is a novel devoid of conflict, and so it is. It portrays a genteel and leisurely world free of aggression and menace“. Bowman, „Fontane's ,Der Stechlin““, 881. Dabei übersieht er jedoch, dass das Potenzial für Konflikte sehr wohl vorhanden ist, diese jedoch durch eine überdeutliche Leserführung durch den Erzähler sozusagen prophylaktisch dementiert werden. In der Konsequenzlosigkeit der Handlungen und der Macht des discourse über die story lässt sich eine weitere Verwendung modernistischer Erzählverfahren, die gerade bei Robert Walser zentral sind, feststellen. 
sozialer und politischer Art sehen. ${ }^{143}$ Unter der Oberfläche der harmonischen Ordnung ist durchaus eine Ambivalenz am Werk, die jederzeit ausbrechen und sichtbar werden kann. Ambivalenz wird nur im Rahmen der Erzählung kontrolliert und für diese Kontrolle braucht es an manchen Stellen Hilfe von der nächsthöheren narrativen Ebene. Wenn Armgard Melusine fragt, ob diese ihr Woldemar gönne und Melusine bejaht, so wird durch die bloße Frage auch die Möglichkeit eines Neins mitgesagt. Der Konflikt ist in den Bereich des Möglichen gerückt, gerade dadurch, dass er explizit verneint wird. So steht auch die Möglichkeit im Raum, dass diese Ordnung nichts weiter als eine glänzende Oberfläche ist, unter der eine für die Ordnung kritische Unruhe herrscht. ${ }^{144}$ In der Künstlichkeit wird die Prekarität des Erzählens sichtbar. Dass die Hoffnung auf eine Fortführung der Ordnung mit diesen Verfahren nur begrenzt angebracht ist, zeigt sich auch im Folgenden. Den industriellen und technischen Entwicklungen der Moderne begegnen die Figuren auf ähnlich ambivalente Weise.

\subsection{Die Kälte der modernen Technik}

Die Auseinandersetzung mit der Moderne findet in der Episode Eierhäuschen, in welcher technischer Fortschritt und Industrialisierung diskutiert werden, eine konkrete Ausgestaltung. Woldemar, Melusine und Armgard, Graf Barby selbst und die Berchtesgadens, Freunde des Hauses Barby, unternehmen einen Ausflug zum Eierhäuschen, einem Ausflugslokal außerhalb Berlins direkt an der Spree. Die Ausflügler spazieren die Spree entlang und kommen auf die am gegenüberliegenden Flussufer angesiedelte Firma Spindler zu sprechen, die moderne Wäschereien und Färbereien führt. Die Firma W. Spindler Wäscherei, Färberei und chemische Reinigung war um die Jahrhundertwende das größte Wäscherei- und Färberei-Unternehmen des Deutschen Kaiserreichs. Paradigmatisch kann es für die moderne industrielle Entwicklung stehen. Die W. Spindler hatte einen sozialen Anspruch und schuf einige Einrichtungen zum Wohlergehen der Arbeiter, ebenso wie preisgünstigen Wohnraum in der Nähe des Arbeitsplatzes, was Fontane sicherlich bekannt war. ${ }^{145}$

143 Vgl. dazu wieder Bowman, der den inhärenten Widerspruch zwischen der stechlinschen "Gesinnung" der Offenheit gegenüber anderen Haltungen und den schematischen Einschränkungen auf der Darstellungsebene betont (weite und enge Seelen, positive und lächerliche Figuren). Bowman, „Fontane's ,Der Stechlin“.

144 Siehe Kap. 2.7 Der Ausbruch - kontrollierte Ambivalenz?, S. 8off. unten.

145 Vgl. Sigurd Paul Scheichl, „Eierhäuschen und Spindlersfelde. Die Welt der Industrie in Fontanes ,Stechlin“', in Industriekulturen. Literatur, Kunst und Gesellschaft, hg. von Marcin Golaszewski und Kalina Kupczynska (Frankfurt am Main u. a.: Peter Lang, 2012), 139-151. 
Im Stechlin jedenfalls fungiert das Unternehmen als das saubere Gesicht der Industrialisierung, deren Folgen, das Arbeiterelend in den Mietskasernen, nicht gezeigt wird.

Angesichts dieser Fabrik auf der anderen Seite der Spree entfaltet sich, ausgelöst von der Baronin Berchtesgaden, ein Gespräch über die Vor- und Nachteile der günstigen Massenproduktion. Die Baronin argumentiert, dass zwar die Massenproduktion die Kleidung einfacher zugänglich mache, dass jedoch der Distinktionswert der Kleidung sinke. Die Ambivalenz der industriellen Modeproduktion für den Adel und die Oberschicht bringt die Baronin Berchtesgaden wie folgt auf den Punkt: „Unser Freund in Spindlersfelde da drüben degradiert uns vielleicht auch durch das, was er so hilfreich für uns thut." (DS 138) Weder Melusine noch Armgard zeigen Interesse daran, ihre Meinungen auf diese Ausführungen der Baronin kundzutun. Armgard schweigt und Melusine gibt die Frage weiter:

Diese [Melusine] gab kopfschüttelnd die Frage weiter und drang darauf, daß die beiden älteren Herren [Barby und Berchtesgaden], die mittlerweile herangekommen waren, den Ausschlag geben sollten. Aber der alte Graf wollte davon nichts wissen. „Das sind Doktorfragen. Auf derlei Dinge lass' ich mich nicht ein.“ (DS 138 )

Der alte Barby weicht der Frage ebenfalls aus. Bei der Ambivalenz der ,Doktorfrage kann er nur verlieren, ist es doch eine unaufhaltbare Entwicklung, die bei genauerer Betrachtung für ihn ungemütlich werden muss. Das Verhalten Barbys, der Dubslav sehr verwandt ist, scheint das Muster der Erzählung zu sein: Das schwierige Thema wird fallengelassen. ${ }^{146}$ Mit einem abrupten

Scheichl beschreibt die Darstellung der modernen Technik als „ein weiteres understatement in Hinblick auf den zentralen Themenkomplex des historischen Wandels, des Endes der elitären Gemütlichkeit im Eierhäuschen“. Scheichl, 148. Hervorhebung i. O.

146 Auch in Effi Briest wird eine „Doktorfrage“ gestellt. Gegen Ende des 34. Kapitels gehen Effi und Niemeyer spazieren: „Von fern her hörte man den Kuckuck, und Effi zählte, wie vielemale er rief. Sie hatte sich an Niemeyer's Arm gehängt und sagte: ,Ja, da ruft der Kuckuck. Ich mag ihn nicht befragen. Sagen Sie, Freund, was halten Sie vom Leben?' ,Ach, liebe Effi, mit solchen Doktorfragen darfst du mir nicht kommen. [...] Was ich vom Leben halte? Viel und wenig. Mitunter ist es recht viel und mitunter ist es recht wenig." Theodor Fontane, Effi Briest, in Theodor Fontane. Große Brandenburger Ausgabe, hg. von Gotthard Erler, fortgeführt von Gabriele Radecke und Heinrich Detering, Bd. 1.15, hg. von Christine Hehle (Berlin: Aufbau, 1998), 332. Es wird hier also wiederum auf eine grundsätzliche Ambivalenz hingewiesen, wenn auch in einem noch grundsätzlicheren Sinn als bei der Moderne-Diskussion im Stechlin. Diese Ambivalenz wird bildlich darin aufgefangen, dass sich Effi unmittelbar nach diesem Dialog auf ihre alte Schaukel setzt und zu schaukeln beginnt. 
Szenenwechsel lenkt die Erzählung zu Robinson, dem Kutscher der Berchtesgadens, und Frau Imme, der Frau des Kutschers der Barbys, die sich über die bevorstehende Entscheidung Woldemars bezüglich Melusine oder Armgard unterhalten. Anstatt die Ambivalenz von Technik und Moderne zur Fortsetzung der Geschichte zu nutzen, zieht die Erzählung programmatisch das Register der Liebesgeschichte dem zeitgenössisch relevanten Diskurs vor. ${ }^{147}$ Die Erzählung weicht den Fragen der Moderne und der sie auszeichnenden Unordnung aus, wie den mit der Mode und damit verbundenen Themen der Demokratisierung und Vermischung der Stände. Sie positioniert sich performativ auf der Seite der Ordnung, indem sie das moderne Ordnungsproblem, das an dieser Stelle explizit aufgeworfen wird, im Gefolge Barbys übergeht. Der Ordnungsversuch durch den Szenenwechsel ist eine Beteuerung, analog zu der Versicherung Melusines, dass sie Armgard Woldemar gönne. Die Ambivalenz, zu der die Moderne, hier konkret die moderne Technik, führt, bleibt bestehen.

Nach einem weiteren Szenenwechsel zum „Eierhäuschen“ wird die Diskussion über Technik in einer Gegenüberstellung von Sonnenlicht und elektrischem Licht wieder aufgenommen.

[Baronin Berchtesgaden:] „Was Sonnenuntergang! den seh’ ich jeden Abend. Ich sitze hier sehr gut und freue mich schon auf die Lichter."

Und nicht lange mehr, so waren diese Lichter auch wirklich da. Nicht nur das ganze Lokal erhellte sich, sondern auch auf dem drüben am andern Ufer sich hinziehenden Eisenbahndamme zeigten sich allmählich die verschiedenfarbigen Signale, während mitten auf der Spree, wo Schleppdampfer die Kähne zogen, ein verblaktes Rot aus den Kajütenfenstern hervorglühte. Dabei wurde es kühl, und die Damen wickelten sich in ihre Plaids und Mäntel.

Auch die Herren fröstelten ein wenig [...]. (DS 144)

Der Sonnenuntergang hat gemäß der Baronin durch seine Alltäglichkeit an Bedeutung verloren, während die elektrischen Lichter einzigartig scheinen. Sie zieht das technische Wunder der Naturerfahrung vor, die Magie der Technik ersetzt ihr diejenige der Natur. Jedoch macht der Anblick dieser Technik die Ausflügler frösteln: Das ,Signal' dafür ist die kalte Sprache der technischen Erscheinungen: Die Farben sind verblakt, verrußt und glühen in der Ferne als ein modernes Purgatorium. Die Moderne und ihre Technik sind zwar zauberhaft, aber bleiben kalt und emotionslos. Die Ausflügler wärmen sich schließlich an einem heißen Punsch, den Woldemar bestellt hat.

147 Dass die beiden auf Melusine tippen, ist ein weiteres Indiz für die Ordnungspolitik des Romans: Imme und Robinson gehören anderen Milieus an und verfügen dementsprechend nicht über den Habitus, der ihnen die richtige Voraussicht erlaubt. 
Als wenig später Melusine in einem neckischen Austausch mit Woldemar von "Luftschifferschlachten“ schwärmt und erklärt, dass sie sich "in solche Vorstellungen geradezu verlieben“ (DS 148) könne, wird sie von der Baronin zurechtgewiesen: „Sie verlieben sich in solche Vorstellungen und vergessen darüber die Wirklichkeiten und sogar unser Programm." (DS 148) Dass Melusine in ihrer Begeisterung für die technischen Möglichkeiten der Wirklichkeit mehr zugewandt ist als die Baronin, ist deutlich. Auch der Versuch, das Gespräch auf den Pastor Lorenzen umzuleiten und so weiteren Gesprächsirritationen zu entgehen, misslingt insofern, als Fontane diesen als Modernen, eine Art „Aëronaut[]en“ (DS 149), aufleben lässt.

Die Moderne als ambivalentes Thema wird so in den Figurenreden und von der Erzählerstimme immer wieder abgewendet. Kritische Gesprächspunkte müssen diplomatisch umschifft werden. So ergibt sich ein komplexes Spiel des Aufdeckens und Verdeckens von Ambivalenz und Kontingenz auf verschiedenen narrativen Ebenen.

Neben dem Diskurs um die technischen Aspekte der Moderne und deren Folgen wird auch die Ehe von Woldemar aufgenommen. Wie zuvor bei Mr. Robinson und Frau Imme scheint auch beim Ausflug zum Eierhäuschen Melusine im Vorteil zu sein. Am Ende des Kapitels stellt Baron Berchtesgaden Melusine die Frage, ob „es denn eine Verlobung gegeben“ habe. Diese antwortet keck: „Nein ... noch nicht“ (DS 151). Gezielt und äußerst subtil wird auf diese Weise die Ambivalenz genährt. Auf der Makroebene der Erzählstränge wird dadurch, wie nebenbei, der Diskurs um die Moderne von der Liebesgeschichte abgelöst. Die Erzählung kann so am Schluss des Kapitels sicherstellen, dass die sprichwörtliche Wärme der Liebe junger Leute über die kühle Moderne die Oberhand behält.

\section{4 "Siegen ist gut, aber zu Tische gehen ist noch besser". Die irrelevante Politik}

Neben der Institution der Ehe als Ordnungsinstrument in Liebesdingen ist auch die Politik ein Brennpunkt von Ordnungen. Ganz grundsätzlich geht es in der Politik um die Auseinandersetzung mit der Frage der angemessenen gesellschaftlichen Ordnung und deren Umsetzung. ${ }^{148}$ Vor diesem Hintergrund

\footnotetext{
148 Vgl. dazu Andreas Anter: „Diese Prägung des modernen politischen Denkens ist ein Spiegel der Tatsache, daß politisches Handeln stets auf das grundlegende Problem der Ordnung gerichtet war und ist - selbst dann, wenn es auf die Abschaffung der Ordnung
} 
bietet es sich an, die Episode um die Wahlen im Stechlin als Metakommentar zum Ordnungsproblem zu lesen. Die Darstellung politischer Prozesse im Roman könnte als Figuration von Ordnung im Allgemeinen interpretiert werden. Der Roman betont jedoch gerade die Machtlosigkeit der Politik und deren absurde Unordnung.

Fontane hat seinen Stechlin, wie erwähnt, zweimal als „politischen Roman“ bezeichnet und in diesem Zusammenhang auf den Adel Bezug genommen. ${ }^{149}$ Es handle sich beim Stechlin um eine "Gegenüberstellung von Adel, wie er bei uns sein sollte und wie er ist" ${ }^{\prime 150}$ Der Stechlin ist tatsächlich in mehrfacher Hinsicht politisch: Er spielt in einer politischen Umbruchphase, verhandelt implizit verschiedene politische Systeme und reflektiert seine eigene narrative Ordnungspolitik. ${ }^{151}$ Konkret finden Wahlen für den Reichstag in der Grafschaft Ruppin, im fiktiven Wahlkreis Rheinsberg-Wutz, statt, in denen sich Dubslav empfiehlt. Der alte Dubslav von Stechlin lässt sich mehr oder weniger freiwillig als Kandidat für die Konservativen aufstellen, verliert dann aber die Wahl gegen die Sozialdemokraten. ${ }^{152}$

Zur Zeit der Niederschrift des Stechlin in den Jahren von 1895 bis 1897 ist im Deutschen Kaiserreich vieles im Umbruch. Die Soziale Frage, die Situation des Vierten Standes und die Politisierung der Arbeiter führten zu einer kontinuierlichen Zunahme der Sozialdemokraten unter Wilhelm II. Sie gewannen in den historischen Reichstagswahlen von 1893, respektive 1898, während die etablierten Parteien Stimmen verloren. Diese Situation wird im Stechlin im

zielte. [...] Folgt man diesem Verständnis, dann ist Ordnung das Telos des Politischen schlechthin." Anter, Die Macht der Ordnung, 1.

149 Siehe Kap. 2 Kontrollierte Ambivalenz. Theodor Fontanes Der Stechlin, S. $39 \mathrm{ff}$. oben.

150 Brief an Carl Robert Lessing, Karlsbad, 8.6.1896, in: DS 395. Hervorhebung i. O.

151 Vgl. dazu Isabel Nottinger: „Das politische Element im Stechlin besteht nicht [...] in den tendenziösen, zweckgerichteten politischen Ansinnen, wie sie von den Naturalisten vertreten werden. [...] Die politische Dimension des Stechlin besteht vielmehr in der Analyse der Gesellschaft kurz vor der Jahrhundertwende." Nottinger, Fontanes Fin de Siècle, 88. Dies trifft sicherlich zu, greift jedoch zu kurz. Es ist nicht angemessen, den Roman nur als objektiv deskriptiv und wertneutral zu beschreiben. Vielmehr verfolgt er durchaus ein Programm, das sich zwar nicht mit dem politischen Programm einer Partei deckt, jedoch eine klare Wertung vollzieht, in dem er "Gesinnung“ und „Herz“ als Werte etabliert, die wiederum mit einem gewissen Habitus zusammenhängen. Siehe Kap. 2.6 „Gesinnung“, „Herz" und „ein ewig Gesetzliches“. Die Ordnung des Stechlin, S. $76 \mathrm{ff}$. unten.

$15^{2} \mathrm{Zu}$ den politischen Ansichten und Wandlungen Fontanes vgl. Gudrun Loster-Schneider, Der Erzähler Fontane. Seine politischen Positionen in den Jahren 1864-1898 und ihre ästhetische Vermittlung (Tübingen: Gunter Narr Verlag, 1986). 
Umstand gespiegelt, dass Dubslav als Vertreter der Konservativen, wie bereits erwähnt, gegen den Sozialdemokraten Torgelow verliert. ${ }^{153}$

Es ist in der Politik eine weitverbreitete rhetorische Strategie, die jeweils andere Ordnung aus einer systemimmanenten Perspektive als Unordnung darzustellen. ${ }^{154}$ Diese Strategie wird auch im Stechlin vielfach angewandt. Obwohl im Roman die konservative Haltung dominant ist, werden die politischen Vertreter derselben weder moralisch noch ideologisch oder hinsichtlich ihrer Integrität oder Fähigkeiten als überlegen dargestellt. Stattdessen zeichnet der Roman das Bild eines grotesk-absurden Schauspiels, das nichts anderes als eine Dekoration der tatsächlichen Machtverhältnisse ist. ${ }^{155}$

\subsection{1 „Was um den Stechlin herum wohnt, das ist für den Stechlin!“ Form statt Inhalt}

Dubslav von Stechlin lässt sich aus bloßem Pflichtgefühl für die Konservativen als Ersatz für den verstorbenen Kortschädel aufstellen. Seine Bedingung ist, dass er weder Reden noch Versammlungen abhalten und besuchen muss. Statt inhaltlichen Positionen stellt er eine Form zur Wahl: sich selbst und seine "Gesinnung“, die nicht näher ausgeführt wird. Nicht mit Taten oder einem Programm, sondern ausschließlich durch seine Identität will er überzeugen. Darin äußert sich durchaus eine herrschaftliche Haltung. Ihm werden denn auch, aufgrund seiner allgemeinen Beliebtheit, die besten Wahlchancen unter den Konservativen attestiert.

Wenn im Roman auch den Konservativen deutlich die Sympathie und vor allem der Raum zu sprechen gegeben wird, so werden sie doch zwiespältig gezeichnet. Die Mitglieder der konservativen Partei sind weder Helden noch

153 Vgl. dazu Eda Sagarra: „Fontanes Gespür für die Prozesshaftigkeit der Zeitgeschichte am Beispiel der Wahlen wird besonders deutlich an seiner Gestaltung der Rheinsberger Wahlen im Stechlin.“ Eda Sagarra, „Geschichte als Prozess. Von der Honoratiorenpartei zur Massendemokratie. Wahlen und Wähler beim späten Fontane“, Fontane-Blätter 76 (2003): 52. Vgl. dazu auch Eda Sagarra, „Der Stechlin' (1898): History and Contemporary History in Theodor Fontane's Last Novel“, The Modern Language Review 87, Nr. 1 (Januar 1992): 122.

154 Insbesondere der Anarchismus wird um die Jahrhundertwende als absolute Unordnung und Chaos stiftende Bewegung dargestellt, während die Theoretiker des Anarchismus denselben als die höchste Ordnung konzeptualisieren. Siehe FN 61, S. 26f. oben.

155 Dazu noch einmal Eda Sagarra: „Die vier Wahlkapitel im Stechlin kann man (auch) als komisches Intermezzo lesen. Die offensichtliche Lust des Autors an der Schrulligkeit der eigenen Figuren [...] sorgt für eine unterhaltsame Lektüre. Die Porträtierung dieser ,Elite‘ des Wahlkreises, alles ältere Herren, bei deren Beschreibung Fontane gemütlich lange verweilt, grenzt ans Absurde, ja, gelegentlich bei dieser oder jener ,Autoritätsfigur' gar ans Groteske.“ Sagarra, „Geschichte als Prozess. Von der Honoratiorenpartei zur Massendemokratie“, 54 . 
Bösewichte, sondern lassen sich am ehesten als leicht dümmliche und gelangweilte bis zynische Menschen beschreiben, oder, um Dubslavs Bezeichnung von Adelheid aufzunehmen, als ,petrefakte' Hampelmänner. Dies wird insbesondere an den zwei Exponenten Kluckhuhn und dem neureichen Gundermann deutlich, die während der Versammlung der Konservativen Reden halten; Inhalt und Redeweise sind sarkastisch überzeichnet, so dass ihre Positionen kaum ernst genommen werden können. Bei einer Versammlung der Konservativen zur Beratung des weiteren Vorgehens im "Stechliner Krug“ heißt es:

Wie Gundermann immer der Sozialdemokratie das „Wasser abstellen“ wollte, so verglich Kluckhuhn alles zur Sozialdemokratie Gehörige mit dem schwarzen Ungetüm im Alsensund. „Ich sag' euch, was sie jetzt die soziale Revolution nennen, das liegt neben uns wie damals Rolf Krake; Bebel wartet bloß, und mit eins fegt er dazwischen." (DS 162)

Wie Gundermann, der vor dem „Wasser auf [den] Mühlen der Sozialdemokratie" ${ }^{156}$ warnt, benutzt auch Kluckhuhn auf das Element Wasser bezogene Analogien. Er vergleicht die Sozialdemokratie im Allgemeinen und August Bebel im Besonderen - den für seine Rhetorik bekannten Redner und Mitbegründer der Sozialdemokratie - mit dem imposanten Kriegsschiff Rolf Krake, welches jederzeit losschießen könne. Dieser nautische Vergleich ist entlarvend: Zum einen ist die Bildlichkeit übertrieben drastisch, zum anderen stimmt der historische Bezug nicht. Das historische Kriegsschiff hatte 1894 den preußischen Vorstoß auf Dänemark nicht verhindert, sondern sich angesichts der Übermacht der Preußen zurückgezogen. Mit der Wiederholung der Phrasen wird die Lächerlichkeit der zwei Redner umso deutlicher gemacht. Dazu kommt, dass diese Sätze und Wendungen in ihren steten Wiederholungen humoristisch leerlaufen. ${ }^{157}$ Jedoch disqualifiziert dieser Sprachgebrauch weder

${ }_{15} 6$ Vgl. zu dieser Redewendung den Aufsatz von Wulf Wülfing, „,Wasser auf die Mühlen der Sozialdemokratie'. Zur politischen Bildlichkeit Theodor Fontanes", in Theodor Fontane. Am Ende des Jahrhunderts, hg. von Hanna Delf von Wolzogen, Bd. 1: Der Preuße, die Juden, das Nationale, 3 Bde. (Würzburg: Königshausen \& Neumann, 200o), 81-96.

157 Am übermäßigen Gebrauch von Sprichwörtern wird im Stechlin vielfach auf die Entleerung von Bedeutung der Reden zahlreicher Figuren hingewiesen. Weisheiten werden zu leeren Worthülsen, die potenzielle Konflikte und Differenzen auffüllen. Damit einher gehen auch die zahlreichen Zitate in den Figurenreden: „This sensitivity [der Figuren gegenüber der Sprache; L. G.] takes many forms, of which perhaps the most immediately striking is the way characters weave into their speech a prodigious number of quotations from literary and other sources, almost always with ironical intent. [...] Just as ironic literary quotations travesty high-mindedness, parodic maxims satirize the truth claims of aphoristic discourse, and this tallies with Dubslav's skepticism of ,sogenannte „richtige“ 
Gundermann noch Kluckhuhn: Trotz der Groteske können sich die beiden der Sympathie des Erzählers gewiss sein. ${ }^{158}$

Unter den grotesken Figuren der Versammlung der Konservativen selbst sind es Pastor Lorenzen und der vielgereiste und kunstverständige Koseleger, welche die größte ironische Distanz an den Tag legen. Letzterer kann sich ein Lächeln angesichts der absurden Vorkommnisse nicht verkneifen: „Um des Superintendenten Mund war ein leiser ironischer Zug." (DS 164)

Wie Gundermann und Kluckhuhn, so werden auch die weiteren Mitglieder der Konservativen allesamt als ein gemütlicher Haufen geschildert, der gerne isst und trinkt, aber sich beileibe nicht mit Arbeit und zu viel Nachdenken aufhalten will und alles in allem, trotz gelegentlicher Ränkespiele, harmlos ist und dilettantisch vorgeht.

Verbindendes Element dieser disparaten Gesellschaft ist der Stechlin in seiner ganzen Polysemantik. Nicht umsonst ruft Krippenstapel in seiner Rede vor den Konservativen: „[W] as um den Stechlin herum wohnt, das ist für den Stechlin" (DS 164, Hervorhebung i. O.). Der Begriff Stechlin setzt eine Proliferation von Semantiken frei, die für ein Gefühl des Zusammenhalts, der Bindung und der Kontinuität stehen: Er umfasst Vater, Sohn und Familie, den See, die Ortschaft, das Herrenhaus, insbesondere die Weltanschauung und letztlich auch den Gasthof, in dem es sich die Gesellschaft gut gehen lässt. Wegen dieses aufgeladenen und vielfältigen Geflechts von Bedeutungen, in dem sich jeder wiederfinden kann und wegen der engagierten Vortragsweise, den „Betonungen“ (DS 164) Krippenstapels, findet dieser Schluss „einen ungeheuren Beifall“ (DS 164) in der Versammlung. Der „ungeheure Beifall“ ist

Worte““ Bowman, „Fontane's ,Der Stechlin““, 886f. Dies liest Bowman überzeugend als Strategie zur Distinktion: „Both the systematic configuration of characters and the uniformity of their speech are symptoms of the novel's advocacy of a unified world-view.“ Bowman, 885 .

Dagegen weist Wulf Wülfing gerade darauf hin, wie bei der Wahlveranstaltung die „Rest-Adligen [...] in ihrer selbstgewissen Ignoranz genau jene ,feinen Unterschiedec [Pierre Bourdieus], die ihre Vorfahren über Jahrhunderte hin mühsam aufgebaut haben, um sich durch Exklusion die gesellschaftliche Herrschaft zu sichern" verwischen, indem sie den Digestif mit dem Aperitif vertauschen (vgl. DS 179). Wülfing, „Wasser auf die Mühlen der Sozialdemokratie“, 85f. Diese Feststellungen widersprechen sich jedoch nur auf den ersten Blick. Im Verhalten der Figuren, auf der story-Ebene ist die Welt aus den Fugen, in der Sprache wird sie versuchsweise zusammengehalten.

${ }_{15} 8$ Sogar Gundermann, der hinter Stechlins Rücken eine Verschwörung anzuzetteln versucht, bleibt, als er sich von Stechlin entlarvt glaubt, ganz der Anständige, indem er aufrichtig Scham empfindet und verlegen ist wie ein Schuljunge, der einen Streich begangen und seinen Fehler reuevoll eingesehen hat (vgl. DS 179). 
wiederum in seiner ganzen Vieldeutigkeit von unheimlich und schrecklich bis ungewöhnlich groß zu lesen. Im Adjektiv schwingt mit der primären Bedeutung der Unheimlichkeit auch ein Hinweis auf das Ende der Behaglichkeit des Realismus mit. Mit dem Aufkommen populistischer Massenbewegungen, so wird hier apostrophiert, kündigt sich eine neue Zeit an. ${ }^{159}$ Auf diese Weise wird, wie zuvor für die Liebesgeschichte beschrieben, auch im Politischen das Gegenteil stets mitformuliert. Es wird eine glatte Oberfläche präsentiert, unterhalb derer vieles unklar und unsicher ist.

Als im weiteren Verlauf des Wahltages klar wird, „daß die Sozialdemokraten einen beinahe glänzenden Sieg“ (DS 184) davontragen, lassen sich die Konservativen davon nicht die Laune verderben:

Dubslav nahm es ganz von der heiteren Seite, seine Parteigenossen noch mehr, von denen eigentlich ein jeder dachte: „Siegen ist gut, aber zu Tische gehen ist noch besser." In der That, gegessen mußte werden. Alles sehnte sich danach, bei Forellen und einem guten Chablis die langweilige Prozedur zu vergessen. Und war man erst mit den Forellen fertig, und dämmerte der Rehrücken am Horizont herauf, so war auch der Sekt in Sicht. (DS 184)

Die Konservativen weigern sich, die sich abzeichnende Veränderung wahrzunehmen und die Notwendigkeit einer Reaktion ihrerseits einzusehen. Statt die Niederlage zu analysieren, die möglichen Gründe und die Folgen dieser Wahl zu reflektieren, stürzen sie sich auf den Rehrücken und den Sekt und unterschätzen damit die langfristigen Folgen der Geschehnisse. ${ }^{160}$

159 Dieser Aspekt ließe sich mit Ernesto Laclaus Begriff des „leeren Signifikanten“, der zur Zusammenführung disparater Diskurse in einen Diskurs dienstbar gemacht werden kann, weiterverfolgen. Auch in dieser Hinsicht wäre Der Stechlin ein modernes und hellsichtiges Werk, das Verfahren zur Herstellung von Massenidentitäten darstellt. Vgl. grundsätzlich: Ernesto Laclau, Emanzipation und Differenz (Wien: Turia Kant, 2002); Ernesto Laclau und Chantal Mouffe, Hegemonie und radikale Demokratie. Zur Dekonstruktion des Marxismus, übers. von Michael Hintz, 4., durchges. Aufl., Passagen Philosophie (Wien: Passagen, 2012).

160 Die Figuren nehmen die Wahlniederlage "nicht besonders ernst, weil der Machthebel für sie anderswo liegt“ als im Parlament. Sagarra, "Geschichte als Prozess. Von der Honoratiorenpartei zur Massendemokratie“, 55. Inge Degenhardt sieht in der Gefasstheit, mit der Dubslav die Niederlage anerkennt, sein „Schwanken zwischen staatsbürgerlicher Verpflichtung und politischer Indifferenz" dargestellt. Inge Degenhardt, „Ein Leben ohne Grinsezug? Zum Verhältnis von sozialer Wirklichkeitsperspektive und ästhetischem Postulat in Fontanes ,Stechlin“', in Naturalismus/Ästhetizismus, hg. von Christa Bürger, Peter Bürger und Jochen Schulte-Sasse (Frankfurt am Main: Suhrkamp, 1979), 200. 


\subsubsection{Die korrumpierte Sozialdemokratie}

Auf dem Heimweg von der Wahlveranstaltung begegnet der alte Dubslav einem Vertreter des Vierten Standes. Beinahe überfährt Dubslavs Kutsche „Tuxen, de[n] alte[n] Süffel“ (DS 193), der mitten im Winter betrunken auf der Straße liegt. Dubslavs Fahrer Martin steigt vom Kutschbock und sieht nach dem Betrunkenen, während Dubslav die Zügel hält. Die geschundene Seele wird aufgefordert, sich neben Stechlin ins Innere des Wagens zu setzen, er zieht jedoch den Platz neben Martin auf dem Kutschbock vor. Auf Dubslavs Frage, wen Tuxen gewählt habe, gibt dieser zu, dass er für den Sozialdemokraten und Wahlsieger Torgelow gestimmt habe.

Dubslav lachte. „Für Torgelow, den euch die Berliner hergeschickt haben. Hat er denn schon was für euch gethan?"

„Nei, noch nich.“

„Na, warum denn?“

"Joa, se seggen joa, he will wat för uns duhn un is so sihr för de armen Lüd. Un denn kriegen wi joa'n Stück Tüffelland. Un se seggen ook, he is klöger, as de annern sinn."

„Wird wohl. Aber er is doch noch lange nich so klug, wie ihr dumm seid. Habt ihr denn schon gehungert?"

"Nei, dat grad nich.“

„Na, das kann auch noch kommen.“ (DS 194, Hervorhebung i. O.)

Dubslav gibt Tuxen ein Almosen und schickt ihn nach Hause. Als Vertreter der Oberschicht hat er wenig Interesse daran, dem Vierten Stand zu Besitz und Unabhängigkeit zu verhelfen und sei es nur zu einem Kartoffelfeld zur Selbstversorgung. Diese Szene macht die wenig demokratische Haltung der stechlinschen Gesinnung deutlich. ${ }^{161}$ Der weitere Verlauf der Erzählung scheint Dubslav jedoch recht zu geben und bestätigt die Unmündigkeit der Torgelow-Wähler, werden sie von diesem doch enttäuscht. Es ist „Fußgendarm“ (DS 161) Uncke, der dem nun sterbenskranken Dubslav gegen Ende des Stechlin Bericht darüber erstattet, dass Torgelow im Parlament so „dumm“ gesprochen habe, „dass es die andern geniert“ habe (DS 364). Die „kleinen Leute“ (DS 364) seien nicht zufrieden mit ihm. Es stellt sich heraus, dass Torgelow ein Blender und nicht nur weniger vertrauenswürdig und inkompetenter als die alte

161 Degenhardt betont, dass Fontane einen Weg zwischen der demokratischen Wahl und der Monarchie suchte, ohne die durchaus vorhandenen machtpolitischen Interessen Dubslavs zu erwähnen: „Die als Farce dargestellte Wahl zeigt nicht nur das politische Disengagement einer Klasse, sondern die Skepsis des Autors gegenüber einer vom konstitutionellen Liberalismus und der SPD getragenen Wahlrechtsbewegung und gegenüber den Hoffnungen, mit Hilfe des Parlamentarismus die bestehenden Machtverhältnisse ändern zu können.“ Degenhardt, „Ein Leben ohne Grinsezug?, 197. 
Garde der Konservativen, sondern auch peinlich war. Mit den Konservativen wären wenigstens Berechenbarkeit, Würde und Ordnung aufrechterhalten worden. Die Sozialdemokratie, die sich den Kampf für die „kleinen Leute“ auf die Fahnen geschrieben hat, stellt sich als korrumpiert und machtversessen heraus. Auf diesen Bericht Unckes antwortet Dubslav von Stechlin mit gewohnter Ironie:

"Ja," lachte Dubslav, „und wo der nu steht, da sollte ich eigentlich stehen. Aber es is doch besser so. Nu kann Torgelow zeigen, daß er nichts kann. Und die andern auch. Und wenn sie's alle gezeigt haben, na, dann sind wir vielleicht wieder dran und kommen noch mal oben auf, und jeder kriegt Zulage. [...]

Vorläufig aber müssen wir abwarten und den sogenannten ,Ausbruch' verhüten und dafür sorgen, daß die Globsower zufrieden sind. Und wenn wir klug sind, glückt es vielleicht auch. Glauben Sie nicht auch, Uncke, daß es kleine Mittel giebt?“

„Zu Befehl, Herr Major, kleine Mittel giebt es. Es hat's schon.“

„Und welche meinen Sie?"

„Musik, Herr Major, und verlängerte Polizeistunde."

"Ja," lachte Dubslav, „so was hilft. Musik und 'nen Schottschen, dann sind die Mädchen zufrieden."

„Und,“ bestätigte Uncke, „wenn die Mädchens zufrieden sind, Herr Major, dann sind alle zufrieden." (DS 364 , Hervorhebung i. O.)

Es wird hier die patriarchalisch-ständische Ordnung verteidigt, indem die Begehren der Landbevölkerung zynisch als nichtig abgetan werden. Dem „Ausbruch“ als Aufstand soll im Sinn einer Machtpolitik der „kleine[n] Mittel“ begegnet werden. Mit kleinen Justierungen im System, die insbesondere das rigide Sittenreglement betreffen, sollen die Unzufriedenen beruhigt werden, ohne die ganze Ordnung, der Dubslav und seine Entourage ihren Stand verdanken, zu reformieren.

Dass die bestehende Ordnung die richtige ist, wird hier ganz konkret mit der positiv gewerteten Güte der Patriarchen deutlich gemacht sowie mit der dargestellten Unfähigkeit der Sozialdemokraten und der Unmündigkeit der Landbevölkerung, die auf leere Versprechungen hereinfällt, demonstriert. Die Unmündigkeit des Vierten Standes wird auch mit sprachlichen Mitteln gezeigt: Der niederdeutsche Dialekt, der in der Lektüre eine andere Rezeptionshaltung vom Leser fordert, unterstützt das Bild des Unverständlichen und Unvernünftigen formal in der Art und Weise der Äußerung. ${ }^{162}$ Es ist deshalb

162 Ganz nebenbei wird damit auch der durchaus revolutionär ausgerichtete Naturalismus als literarische Bewegung diffamiert. Indem Dubslav und die Erzählung im Gegensatz zum Dialekt Tuxens und Buschens, einer anderen Figur des Vierten Standes, an der kunstvollen Standardsprache und an einem außerordentlichen Bildungshorizont festhalten, 
erstaunlich, dass Der Stechlin in vielen Interpretationen als neutral beschrieben wurde, als ein Text, der sich auf das ,Menschliche' als solches beziehen würde. ${ }^{163}$ Auch wenn die Konservativen im Roman nicht als Heldenfiguren gefeiert werden und obwohl Fontane sich in Briefen vielfach zum Fortschritt und der Dringlichkeit der Sozialen Frage bekannt hat, so ist doch die politische Stoßrichtung an dieser Stelle überdeutlich. ${ }^{164}$

Aus erzählökonomischer Perspektive nimmt die Sequenz um die Wahl in Rheinsberg und die Frage, ob Dubslav gewählt wird, was den weiteren Erzählverlauf tiefgreifend ändern würde, dieselbe Funktion ein, wie zuvor die Liebesgeschichte. Genaugenommen ist die Wahl-Sequenz ein geschlossener Einschub in die Liebesgeschichte. Unmittelbar im Anschluss an die Bekanntgabe der Wahlresultate hebt auch die Spekulation über die Brautwahl Woldemars wieder an. Die Wahl hat die Funktion der Liebesgeschichte, die für diese Dauer konsequent suspendiert wurde, zeitweilig ersetzt und die Erzählung vorangetrieben. Mit denselben Mitteln, wie bei der Ehe-Geschichte um Woldemar, Armgard und Melusine wird bei der politischen Wahl Ambivalenz als Spannungsmoment eingesetzt: Eine kontingente Ausgangslage wird etabliert, die durch gegensätzliche Bewertungen der Wahlwahrscheinlichkeiten und ihrer Folgen ambivalent gehalten wird. Ausgezeichnete Figuren, die der "Gesinnung" Dubslavs entsprechen, lenken die Rezeption in die richtige Richtung. Solche Figuren sind etwa Rex und der alte Barby, die schon, im Gegensatz zu Mr. Robinson und Frau Imme aus tieferen Schichten (vgl. DS 138-143), in der Liebesambivalenz Recht behalten. In der Politik sind es ebenso die gemäßigten und wohltätigen Menschen wie Woldemar,

bezieht Der Stechlin deutlich Stellung. Nur in den Dialogen gibt es einige Einsprengsel von Dialekt. Zwar hat sich Fontane in späten Jahren in Rezensionen durchaus positiv gegenüber dem Naturalismus' Gerhard Hauptmanns geäußert, insbesondere zu dessen Vor Sonnenaufgang, im Stechlin wird die literarische Strömung mit dieser Verwendung des Dialekts jedoch auch ins Lächerliche gezogen. Vgl. Hugo Aust, „Kulturelle Traditionen und Poetik“, in Fontane-Handbuch, hg. von Christian Grawe und Helmuth Nürnberger (Stuttgart: Kröner, 2000), 367-380.

163 Vgl. dazu auch Christian Grawe: „Alles Dargestellte also [...] sind nicht Funktionsträger im Hinblick auf eine Handlung, sondern im Hinblick auf eine ,Idee: auf das Menschliche, wie es sich in einer bestimmten Zeit als historisch Variables und Konstantes ausdrückt, im Hinblick auf den ,Zeitgeist'. [...] Der Roman ist nicht mehr wie bisher eine individuelle Geschichte, verwoben mit dem Zeitbild, sondern es ist dieses Zeitbild selbst, wie es, perspektivisch gebrochen durch die Personen, erscheint.“ Grawe, „Fontanes neues Sprachbewußtsein in ,Der Stechlin““, 42. Die „Einheit des Werks [...] muß durch ein Bezugssystem unterstützt werden, das [...] die gelebten Gesetzlichkeiten des menschlichen Lebens als Thema des Buches signalisiert." Grawe, 43.

164 Vgl. dazu Grevel, „Das Alte und das Neue“. 
Lorenzen und Dubslav selbst, die ahnen, dass Dubslav nicht gewinnt - und Recht behalten. Die Grundargumentation, dass Personen mit entsprechender Nähe zu Dubslav auch dessen Ansicht, dass „Herz“ vor der Vernunft und „Gesinnung" vor der Ideologie kommen, teilen, ist nicht widerspruchsfrei, ist diese "Gesinnung" doch selbst eine Art Ideologie. Wahrheit, Weisheit und Güte werden an einen bestimmten, sozial privilegierten Habitus geknüpft. ${ }^{165}$ Diese Spannung zwischen der Funktion der Sequenz (Spannung und Ordnung zu etablieren) und der Bedeutung, die ihr die Figuren und die Erzählung explizit zuzusprechen scheinen (der bedingungslosen richtigen „Gesinnung“), nimmt einmal mehr das Verhältnis von story und discourse auf: Der Ablauf der Handlung wird von der Art und Weise ihres Erzählens ideologisch überformt.

Durchaus ambivalent gesehen werden auch die Folgen eines Wahlsieges. So reagiert der Sohn Woldemar mit Sorge auf die Kandidatur Dubslavs, als er in einem Brief von Lorenzen davon erfährt.

Woldemar, als er gelesen, wußte nicht recht, wie er sich dazu stellen sollte. Was Lorenzen da schrieb, „daß kein Besserer im Hause sitzen würde“, war richtig; aber er hatte trotzdem Bedenken und Sorge. Der Alte war durchaus kein Politiker, er konnte sich also stark in die Nesseln setzen, ja vielleicht zur komischen Figur werden. Und dieser Gedanke war ihm, dem Sohne, der den Vater schwärmerisch liebte, sehr schmerzlich. Außerdem blieb doch auch immer noch die Möglichkeit, daß er in dem Wahlkampf unterlag.

Diese Bedenken Woldemars waren nur allzu berechtigt. Es stand durchaus nicht fest, daß der alte Dubslav, so beliebt er selbst bei den Gegnern war, als Sieger aus der Wahlschlacht hervorgehen müsse. (DS 159)

Woldemar fürchtet sich sowohl vor einem Sieg als auch vor einer Niederlage seines Vaters. Die Ansicht, dass Dubslav nicht gewinnen könne, erhält im Wechsel vom Modus der erlebten Rede Woldemars hin zur kommentierenden Erzählerrede Unterstützung. Der Erzähler pflichtet Woldemar bei und bestätigt damit noch einmal dessen Bedenken. Zwischen dem Erzähler und Woldemar entsteht dadurch eine besondere Nähe; Woldemar wird als herausragende

165 Dass der Intuition und dem Geschmack nicht universelle Gesetze zugrunde liegen, ist wesentlich für das Habitus-Konzept Pierre Bourdieus. Nach Bourdieu sind Geschmack und Intuition abhängig von der Position im sozialen Raum. Soziologisch betrachtet ist dieser Zusammenhang zwischen Herkunft und Verhaltensweisen sehr deutlich. Vgl. Pierre Bourdieu, Die feinen Unterschiede. Kritik der gesellschaftlichen Urteilskraft, übers. von Bernd Schwibs und Achim Russer (Frankfurt am Main: Suhrkamp, 1982). 
Figur etabliert. Gleichzeitig erreicht der Erzähler eine Selbstbestätigung und kann sich als Erzeuger einer sich selbst bekräftigenden Ordnung darstellen.

Wenn man die Abfolge der narrativen Auflösungen zentraler Ambivalenzen des Romans betrachtet, die von der Ehe-Frage über die Technik zum Wahlkampf und schließlich zur Krankheit Dubslavs reicht, wird deutlich, dass jeweils nur eine Ambivalenz aktiviert ist. Die anderen werden suspendiert oder mit verschiedenen rhetorischen Mitteln als abgeschlossen dargestellt, wie besonders in der Ehe-Geschichte deutlich wurde. Diese strukturelle Priorisierung von Erzählsträngen, die syntagmatisch geschaltet werden, ist bezeichnend für die Ordnungsverfahren des Romans. Die auf story-Ebene sehr komplexen, ambivalent zu bewertenden Geschehnisse und Figuren werden nachvollziehbar und überschaubar erzählt und dadurch in Ordnung gebracht. Etwaige Digressionen sind klar abgegrenzt und greifen nicht auf andere Erzählstränge über. Beispiel dafür ist der eben besprochene Teil „Wahl in Rheinsberg-Wutz“, der im Kontext der Liebesgeschichte als Digression fungiert, die jedoch keinerlei Gefahr darstellt, den ihr im Erzählgefüge zugeteilten Platz über die Maßen zu beanspruchen und in andere Erzählstränge zu wuchern. So entsteht der Eindruck einer ausgeprägten Ordnung des Stoffs und einer starken Souveränität des Erzählers. Die Erzählung weist gleichsam aus, dass sie der Komplexität der Moderne im Genre des Zeitromans gewachsen ist. ${ }^{166}$

\subsection{Ordentliches Erzählen}

Der Stechlin verfügt über narrative Ordnungsstrategien, die subtil, aber mit großer Konsequenz eingesetzt werden. Im Zentrum stehen die fast überdeutlichen Leserführungen mittels Erzählerkommentaren, impliziter Anordnung und Komposition beim Wechsel von Schauplätzen sowie die Bündelung der (Gesprächs-)Themen. Bei Fontane ist die Gestaltung gleichzeitiger Handlungen noch kein darstellerisches Problem. ${ }^{167}$ Die folgenden drei Stellen illustrieren, wie der Erzähler mit der Gleichzeitigkeit von Ereignissen umgeht.

166 Fontanes Beschreibung des Stechlin, die Betonung seiner Handlungsarmut, der ausufernden Gespräche und die lapidare Zusammenfassung in der eingangs zitierten Briefstelle, ist schon als Lenkung der Rezeption in Richtung Ruhe und Gelassenheit zu lesen, die der Roman selbst vertritt. Diese Gelassenheit wird durch gezielte Führung von Spannungsmomenten erzeugt, wodurch der Text sein Ziel in der Anwendung der abgelehnten Mittel erreicht. Vgl. de Man, „Semiologie und Rhetorik“.

167 Dies wird insbesondere in der Avantgarde und der „emphatischen Moderne“ (Moritz Baßler) zu einer wichtigen Problematik, die unterschiedliche Lösungswege generiert, 
Ziemlich um dieselbe Zeit, wo der Telegraphenbote bei Gundermanns vorsprach, um die Bestellung des alten Herrn von Stechlin auszurichten, ritten Woldemar, Rex und Czako, die sich für sechs Uhr angemeldet hatten, in breiter Front von Cremmen ab; Fritz, Woldemars Reitknecht, folgte den dreien. (DS 16)

Während Woldemar und die Domina miteinander plauderten, erst im Tetea-Tete, dann in Gegenwart von Rentmeister Fix, ritten Rex und Czako (Fritz mit dem Leinpferd folgend) auf Cremmen zu. Das war noch eine tüchtige Strecke, gute drei Meilen. (DS 98)

Auch die beiden voranschreitenden Paare waren in lebhaftem Gespräch. (DS 137)

Im ersten Beispiel wird der Simultanität („um dieselbe Zeit“) der Handlungen mit einem Szenenwechsel aus einer Position des Überblicks heraus begegnet. Das zweite Beispiel ist avancierter. Die Bemerkung „das war noch eine tüchtige Strecke" lässt sich sowohl als Erzählkommentar (Nullfokalisierung) wie als erlebte Rede (interne Fokalisierung) der Figuren Rex und Czako lesen. Im letzten Beispiel ist die räumliche Distanz zwischen den Schauplätzen sehr klein - die Barbys, Woldemar und die Berchtesgadens spazieren am Ufer der Spree entlang -, weshalb der Szenenwechsel mit einem minimalistischen „auch“ eingeleitet werden kann. Trotz dieser kaum nennenswerten räumlichen Verschiebung legt der Erzähler Wert darauf, allen Interaktionen der Figuren Platz zu gewähren, Überschneidungen zu verhindern und die Überleitungen möglichst harmonisch und kontrolliert zu gestalten. ${ }^{168}$ Nur selten gibt es Ausnahmen, in denen unvermittelte, collagenartige Einschübe eine ansatzweise disruptive Wirkung haben. Vornehmlich geschieht dies bei Baruch Hirschfeld und dessen Sohn Isidor, den Geldleihern, die die zeittypischen Merkmale des ,Jüdischen' tragen (vgl. DS 11f. und DS 159f.). ${ }^{169}$

etwa im Futurismus Marinettis. Vgl. dazu Kiesel, Geschichte der literarischen Moderne; Baßler, Die Entdeckung der Textur.

Vgl. dazu auch Ortrud Gutjahr, „Kultur der Ungleichzeitigkeit. Theodor Fontanes Berlin-Romane im Kontext der literarischen Moderne", in Theodor Fontane. Am Ende des Jahrhunderts, hg. von Hanna Delf von Wolzogen, Bd. 3: Geschichte, Vergessen, Großstadt, Moderne, 3 Bde. (Würzburg: Königshausen \& Neumann, 2000), 171-188.

168 Man ist versucht zu vermuten, dass diese deutlichen Überleitungen der Publikationsform geschuldet sind, wurde der Roman doch zuerst in der wöchentlich bzw. monatlich erscheinenden Zeitschrift Land und Meer veröffentlicht. Bei einer Gegenüberstellung der Romankapitel und der Zeitschriftenlieferungen zeigt sich jedoch, dass die Überleitungen nicht in Beziehung zur Fortsetzung der Geschichte in den Zeitschriften stehen. Vgl. dazu die Gegenüberstellung „Übersicht über die Erstreckung der Zeitschriftenlieferungen“ von Peter Staengle in DS 389-399.

169 Die Rolle des ,Juden' bei Fontane ist in der jüngeren Forschung intensiv untersucht worden. Vgl. etwa die Beiträge der zweiten Sektion in: Hanna Delf von Wolzogen, Hrsg., Theodor Fontane. Am Ende des Jahrhunderts, Bd. 1: Der Preuße. Die Juden. Das Nationale, 
Neben solchen expliziten, kommentierten Überleitungen gibt es auch implizite, die aus dem Arrangement der Textblöcke hervorgehen. Der dramaturgisch geschickte Erzähler des Stechlin bereitet Handlungssequenzen subtil vor. ${ }^{170}$ Auch dafür gibt es zahlreiche Beispiele, etwa die Einführung der BarbySchwestern in einem Gespräch von Rex und Czako, woraufhin im folgenden Kapitel das Haus der Barbys zum Schauplatz wird. Der Erzähler führt sie über das narrative Arrangement so behutsam ein, dass es keines Kommentars

3 Bde. (Würzburg: Königshausen \& Neumann, 200o). Wolfgang Benz hat den „latenten Antisemitismus“ als "Zeitströmung um die Jahrhundertwende“ herausgearbeitet. Vgl. Wolfgang Benz, „Antisemitismus als Zeitströmung am Ende des Jahrhunderts“, in Theodor Fontane. Am Ende des Jahrhunderts, hg. von Hanna Delf von Wolzogen, Bd. 1: Der Preuße, die Juden, das Nationale, 3 Bde. (Würzburg: Königshausen \& Neumann, 200o), 157-168.

Der „Antisemitismus [...] als öffentliche Chiffre der Selbstverständigung der Mehrheitsgesellschaft" wird durch eine Analyse der jüdischen Namen bei Fontane deutlich gemacht, auch im Stechlin mit Baruch und Isidor Hirschfeld. Benz, 166. Vgl. auch Hans Otto Horch, „Von Cohn zu Isidor. Jüdische Namen und antijüdische Namenspolemik bei Theodor Fontane", in Theodor Fontane. Am Ende des Jahrhunderts, hg. von Hanna Delf von Wolzogen, Bd. 1: Der Preuße, die Juden, das Nationale, 3 Bde. (Würzburg: Königshausen \& Neumann, 2000), 169-181.

Bernd Balzer legt Wert auf die Unterscheidung zwischen dem Bürger und dem Romancier Fontane. Balzer argumentiert, dass Fontane gerade im Stechlin „die Dialektik symmetrischer Gesprächssituationen und [...] die innere Wahrhaftigkeit von Figuren und Handlungskonzeption [...] vor der Fiktionalisierung von Klischees“ bewahrt hätten. Bernd Balzer, „Zugegeben, daß es besser wäre, sie fehlten, oder wären anders, wie sie sind'. Der selbstverständliche Antisemitismus Fontanes", in Theodor Fontane. Am Ende des Jahrhunderts, hg. von Hanna Delf von Wolzogen, Bd. 1: Der Preuße, die Juden, das Nationale, 3 Bde. (Würzburg: Königshausen \& Neumann, 2000), 205. Dabei scheint sowohl die „Symmetrie“ als auch die „Wahrhaftigkeit“, die Balzer im Stechlin erkennt, zu sehr der Rhetorik des Textes selbst geschuldet zu sein. Es ist ein Unterschied, ob sich die Erzählung als solche inszeniert, was sie zweifelsohne tut oder ob sie es tatsächlich ist, was nicht zutrifft: Zu deutlich ist die Asymmetrie des Figurenarrangements, die Ideologie auf Seiten Stechlins; die Künstlichkeit der Konzeption wird geradezu herausgestellt.

Im Zusammenhang dieser Stereotypen ist jüngst auch die Funktion des „Polnischen“ bei Fontane auf Interesse gestoßen: Alexandra Dunkel, Figurationen des Polnischen im Werk Theodor Fontanes (Berlin, Boston: De Gruyter, 2015), https://doi.org/10.1515/9783110422894. Vgl. dazu auch Rolf Parr, „,Der Deutsche, wenn er nicht besoffen ist, ist ein ungeselliges, langweiliges und furchtbar eingebildetes Biest'. Fontanes Sicht der europäischen Nationalstereotypen", in Theodor Fontane. Am Ende des Jahrhunderts, hg. von Hanna Delf von Wolzogen, Bd. 1: Der Preuße, die Juden, das Nationale, 3 Bde. (Würzburg: Königshausen \& Neumann, 2000), 211-226.

170 Der Erzähler ist verantwortlich für die Art und Weise der Informationsvergabe und das Arrangement der Szenen. Diese Elemente fallen bei Wolf Schmid unter die „implizite Darstellung“ des Erzählers. Schmid, Elemente der Narratologie, vgl. zur Diskussion über explizite und implizite Darstellung des Erzählers bes. 72-75. 
mehr bedarf. ${ }^{171}$ Implizite Informationsvermittlung, Anspielungen und Ankündigungen von etwas Kommendem finden sich vielfach; diese Strategien stellen den Inhalt als glatte Oberfläche dar, wodurch Konflikte und Brüche in der Erzählung verdeckt werden.

Diese glatte Oberfläche stellt den Erzähler wiederum umso glaubhafter dar: Die expliziten und impliziten Überleitungen etablieren ihn als vertrauenswürdigen Arrangeur. Im Bekenntnis zu Harmonie und Ordnung der Narration hält sich die Erzählung an die Ordnung, die sie selbst festlegt. Dies äußert sich auch in der großen Nähe zwischen Dubslav und dem Erzähler, die eine reziproke Bestätigung von Verlässlichkeit, eine Garantie für Sympathie und Gutherzigkeit ermöglicht. Die „Gesinnung", die im Stechlin so zentral ist, ist an eine ganz bestimmte Form des Erzählens gekoppelt, die sich wiederum in der Qualität und der Quantität der Figurenreden spiegelt. ${ }^{172}$

Auch wenn der Erzähler nah an den Figuren ist, insbesondere bei Dubslav von Stechlin und dessen Sohn Woldemar, deren Innensichten häufig in erlebter Rede wiedergegeben werden, gibt es doch immer wieder Momente, in denen er die interne Fokalisierung aufgibt und sein auktoriales Potenzial, sein Vermögen zur Nullfokalisierung, zeigt, wie beispielsweise in der Charakterisierung Gundermanns deutlich wird:

An Gundermann ging der Alte ohne Notiznahme vorüber. Dies war aber nur Zufall; er wußte nichts von den Zweideutigkeiten des Siebenmühlners, und nur dieser selbst, weil er ein schlechtes Gewissen hatte, wurde verlegen und empfand des Alten Haltung wie eine Absage. (DS 178f.)

Das Vermögen zur Nullfokalisierung betont die Objektivität des Erzählers, was das Vertrauen in ihn und letztlich in die narrative Ordnung steigert. Der Erzähler kann eine Meta-Position einnehmen, von der aus er das Geschehen überblickt, kann die Figuren gerecht beurteilen und behält die Fäden der Erzählung in der Hand.

Es hat sich oben gezeigt, dass sich die Erzählstränge jeweils durch eine konstitutive Ambivalenz auszeichnen. Auf die Liebesgeschichte, in der die Ambivalenz sich auf die Entscheidung zwischen Armgard und Melusine bezieht, folgt die Wahl in Ruppin, in der die Ambivalenz in den Wahlchancen

171 Nach dem Gespräch über Melusine im zehnten Kapitel folgt nach drei Sternen ein kurzer Absatz zum Ausklingen - passenderweise beim „Billard“ (DS 103). Damit endet der Teil „Kloster Wutz“, der neue - „Nach dem ,Eierhäuschen“ - beginnt sogleich mit dem Haus der Barbys. Vgl. DS 105-151.

172 Durch diese Konstruktion macht sich die Erzählung auch angreifbar: Würde der Leser Dubslav als selbstsüchtigen, zynisch auf seine Pfründe versessenen Machtmenschen sehen, so würde die ganze Erzählform und Erzählordnung in Mitleidenschaft gezogen. 
Dubslavs wirksam ist. Der Erzählstrang der Liebesgeschichte wird nach dem Wahl-Kapitel wieder aufgenommen und mit der Verlobung zwischen Armgard und Woldemar endgültig seinem Ende zugeführt. Es folgen die Diskussion um die technische Moderne und schließlich der letzte Erzählstrang um die Krankheit und das Sterben Dubslavs. Die Erzählstränge lösen sich also ordentlich ab. Wie gezeigt, wird durch diese syntagmatische Ordnung der Erzählstränge der Eindruck von Souveränität erzeugt. Der Erzähler demonstriert, dass er das vielfältige Geschehen ,im Griff' hat, im Erzählen ordnen kann und jeweils angemessene Register zieht, die Handlung rafft, aufschiebt, nacherzählt. Die Technik, die der Erzähler für die Überleitung zwischen den Schauplätzen benutzt, legt nahe, dass der discourse in dieser Erzählordnung nicht zwischen Erzählsträngen hin und her springen kann, sondern dass dem Leser, ohne ihn je direkt anzusprechen, ein räumlich und zeitlich geordnetes Geschehen präsentiert wird, in dem dieser sich orientieren kann. Diese narrativen Techniken sind die Basis der diskursiven Ordentlichkeit des Stechlin und gleichzeitig Basis seiner Künstlichkeit. ${ }^{173}$

\section{6 „Gesinnung“, „Herz“ und „ein ewig Gesetzliches“. Die Ordnung des Stechlin}

Im Stechlin wird an zwei prominenten Stellen auf zeitlose Ordnungen referiert. Das eine ist das Leben und Sterben, das andere das dialektische Verhalten der Jugend gegenüber den Vätern. Ersteres beschreibt Dubslav in Bezug auf sein eigenes Ableben lapidar: „Ein ewig Gesetzliches vollzieht sich“ (DS 371). Dieses ,Gesetzliche' ist die allgemeinmenschliche Ordnung, gegen die sich nichts und niemand stellen kann und der sich auch Dubslavs „Gesinnung“ anschließt. Es

\footnotetext{
173 Anke Kramer betont mit Bezug auf die unzusammenhängenden Gespräche im Stechlin: „Sie [die Gespräche] schweifen ab, springen von einem Thema zu einem anderen und brechen unvermittelt ab. Durch diese Absage an traditionelles Erzählen demonstriert der Roman den wiederholt thematisierten Verlust der, göttlichen Weltordnung a auf der Ebene des discours. Die in den früheren Romanen zur Kontingenzreduktion gebrauchten Verfahren des Vorausdeutens werden zwar noch anzitiert, doch die Hinweise bleiben völlig vage, sie laufen ins Leere und können keinen Zusammenhang mehr stiften.“ Kramer, „Der große Zusammenhang der Dinge“, 19of. Diese Argumentation konzentriert sich auf das digressive Moment der Gespräche und scheint dabei die Ordnungsleistung des discours zu übersehen. Kontingenzreduktion mittels Vorausdeutung des Kommenden wird im Stechlin durchaus angewandt, wie etwa in der subtilen Zuordnung von Wissen zu den jeweiligen gesellschaftlichen Positionen, was eine deutliche Lenkung und Kontingenzreduktion impliziert.
} 
ist die Vorstellung einer ewigen Ordnung, welche die unzuverlässigen, wandelbaren Ordnungen, wie etwa diejenige der Politik, überdauert.

Als der alte Dubslav schon schwer erkrankt ist, ruft er noch einmal den Pastor Lorenzen zu sich, um mit ihm sein „Hauptthema“ (DS 366 ) zu besprechen, das im Bewahren des Alten, der Ordnung als solcher kulminiert. In diesem Gespräch wird deutlich, wie sich Dubslav die Abwesenheit dieser Ordnung vorstellt. Er formuliert in seiner Angst, dass Woldemar, dieser „unsichere Passagier[]“ (DS 367) sich von den Ideen der Moderne anstecken lassen, die Bescheidenheit verlieren und sich zu sehr am Neuen orientieren könnte, folgende Schreckensvision:

Und dann ist da ein Professor, Kathedersozialist, von dem kein Mensch weiß, ob er die Gesellschaft einrenken oder aus den Fugen bringen will, und führt eine Adelige, mit kurzgeschnittenem Haar (die natürlich schriftstellert) zur Quadrille. Und dann bewegen sich da noch ein Afrikareisender, ein Architekt und ein Portraitmaler, und wenn sie nach den ersten Tänzen eine Pause machen, dann stellen sie ein lebendes Bild, wo ein Wilddieb von einem Edelmann erschossen wird, oder sie führen ein französisches Stück auf, das die Dame mit dem kurzgeschnittenen Haar übersetzt hat, ein sogenanntes Ehebruchsdrama, drin eine Advokatenfrau gefeiert wird, weil sie ihren Mann mit einem Taschenrevolver über den Haufen geschossen hat. (DS 367 )

Mit dieser Vision eines modernen intermedialen Happenings führt Dubslav plastisch vor, wie er sich das Neue als Schreckgespenst der Unordnung vorstellt. Elemente, die nicht in seine alte Ordnung passen, wie Kurzhaarschnitte für Frauen, gewalttätige Frauen, Exotik und neue Theaterformen werden nebeneinandergestellt. Es sind Elemente, die nicht mehr durch einen ordnenden Erzähler harmonisiert werden. Dubslavs Darstellung ist eine modernistische Binnenerzählung, in der die Orientierung durch einen allwissenden Erzähler nicht länger gegeben ist, eine Erzählung mit Figuren ohne klaren Intentionen und Anstand, die in ihrer Exotik den Regionalismus als Herkunftskonzept sprengen. Die Aufzählungen, verknüpft bloß mit einem „und dann“, haben keinen inneren Zusammenhang mehr, der im Stechlin und von Dubslav etwa mit dem unterirdisch in alle Welt verbundenen Stechlinsee so kunstvoll postuliert wurde. Dieser "große[] Zusammenhang der Dinge“ ist jedoch gerade das, was Melusine in ihrem Gespräch mit Lorenzen als Essenz des Sees wie der Geschichte bestimmt: „Und vor allem sollen wir, wie der Stechlin uns lehrt, den großen Zusammenhang der Dinge nie vergessen. Sich abschließen, heißt sich einmauern, und sich einmauern ist der Tod." (DS 263)

Pastor Lorenzen jedoch vermag es, Dubslav von Stechlin hinsichtlich seiner Befürchtung, sein Nachfolger Woldemar würde das Alte verabschieden, zu beruhigen. Lorenzen erklärt Dubslav das übergeordnete Generationenprinzip, 
dem gemäß der Nachfolger zunächst eine große Veränderung herbeiführen wolle, dann aber zum Alten des Vorgängers zurückkehren werde. Zwar werde Woldemar einen „leidlich ehrlichen Versuch [unternehmen], als Neugestalter aufzutreten und [...] ein Volksbeglückungsprogramm auch wirklich aus der Tasche“ (DS 368) holen. Bald jedoch, schon „nach einem halben Jahre lenkt der Neuerer wieder in alte Bahnen und Geleise ein.“ (DS 368 )

Die Prognose Lorenzens wird bestätigt, wenn Armgard und Woldemar nach wenigen Monaten aus der Stadt wieder zurück nach Stechlin ziehen. Armgard waren die Zerstreuungen der Großstadt doch zu wenig spannend gewesen und Woldemar "hätte nichts Lieberes hören können“ (DS 386). Er kündigt den Dienst im Militär, da er, „[l]iebenswürdig und bescheiden wie er war [...], nicht berufen sei, jemals eine Generalstabsgröße zu werden“ (DS 386). Woldemar wählt das Alte, wie es sich in seiner Brautwahl abzeichnete. Diese Weichenstellung wird noch dadurch bestätigt, dass das Mädchen Agnes mit seinen revolutionären roten Socken, die Dubslav in seiner Krankheit zu Diensten war und vor der sich Adelheid so gefürchtet hat, nicht im Haus aufgenommen wird. ${ }^{174}$

„Die Gesinnung entscheidet“ (DS 340), ob etwas gut oder schlecht sei, sagt Lorenzen an einer Stelle zu Dubslav von Stechlin. ${ }^{175}$ Das heißt auch, dass nicht mehr einfach der Stand und das Milieu die Identität und den Wert einer Person bestimmen. Diese Vorstellung entspricht Lorenzens Definition alles Modernen als Selbstbestimmung gegenüber dem Alten als Fremdbestimmung. ${ }^{176}$ Worin die "Gesinnung“ zu bestehen hat, erläutert er in der Totenrede auf Dubslav:

174 Edda Ziegler beschreibt Agnes als „Hoffnungsträgerin“. Ziegler, „Die Zukunft der Melusinen“, 181. Für Adelheid sei sie „Inbegriff aller Gefahr für Preußens Zukunft und die drohende Umwälzung althergebrachter Sitte und Ordnung“. Dubslav jedoch setze diese „Opposition gezielt ein, um die ,pretrefakte‘ Adelheid, Symbolfigur eines ausschließlich rückwärts gewandten Preußentum ohne Zukunft, [...] zu vertreiben." Im Unterschied zu Melusine und Armgard sei Agnes "selbstbewußt und selbstbestimmt" und „nicht gebunden an die Väter“. Zwar erlaubt die Gestaltung Agnes durchaus diese positiven Konnotationen. Gleichzeitig ist Agnes, als sie Dubslav versorgt, wenig freudig bei der Sache, sie wirkt gelangweilt und gegenüber Dubslav eher abgeneigt. Hinzu kommt, dass sie am Schluss in das „Rettungshaus“ der radikalen und heuchlerischen Christen Ermyntrud Katzler und Koseleger gegeben und so erst recht zum Feind des Adels gemacht wird. Vgl. Bowman, „Fontane's ,Der Stechlin“', 890.

175 „Ich weiß nicht, Herr von Stechlin. Echtes Heldentum, oder um's noch einmal einzuschränken, ein solches, das mich persönlich hinreißen soll, steht immer im Dienst einer Eigenidee, eines allereigensten Entschlusses. Auch dann noch (ja mitunter dann erst recht), wenn dieser Entschluß schon das Verbrechen streift. [...] Mit andern Worten, ein Niedrigstes als Höchstes. Die Gesinnung entscheidet.“ (DS 340)

176 Vgl. dazu: „Der Hauptgegensatz alles Modernen gegen das Alte besteht darin, daß die Menschen nicht mehr durch ihre Geburt auf den von ihnen einzunehmenden Platz 
Sein Leben lag aufgeschlagen da, nichts verbarg sich, weil sich nichts zu verbergen brauchte. Sah man ihn, so schien er ein Alter, auch in dem, wie er Zeit und Leben ansah; aber für die, die sein wahres Wesen kannten, war er kein Alter, freilich auch kein Neuer. Er hatte vielmehr das, was über alles Zeitliche hinaus liegt, was immer gilt und immer gelten wird: ein Herz. Er war kein Programmedelmann, kein Edelmann nach der Schablone, wohl aber ein Edelmann nach jenem alles Beste umschließenden Etwas, das Gesinnung heißt. (DS 376)

Mit dieser Wendung wird die Ambivalenz der Figur Dubslavs von Stechlin konkretisiert - er ist weder alt noch neu -, eine Ambivalenz, die ihn schließlich über die Frage nach weltlichen und historischen Haltungen hinaushebt. Was über „alles Zeitliche“ hinausgeht und somit unbedingt gilt, ist das „Herz“. Lorenzen formuliert eine eigentliche Utopie der Ordnung des Herzens und der Gesinnung. Diese Ordnung bleibt zwangsläufig vage. Die inhaltliche Offenheit ermöglicht es ihr, den festen Zuschreibungen von vergänglichen Weltanschauungen zu entgehen und sich stattdessen am Einzelfall auszurichten. Der Einzelfall führt zum Individuum, das in der Moderne und ihrem zunehmenden Individualismus wiederum als neuer ordnungsrelevanter Aspekt zu betrachten ist. Wenn Herkunft und Stände im Stechlin auch nach wie vor eine zentrale Rolle spielen für die Identität, so verlieren sie doch ihre Vormachtstellung.

Was mit der eigentlich inhaltsleeren „Gesinnung“ bezeichnet wird, ist das Prinzip des Zusammenhangs aller Elemente. Wie im Symbol des Stechliner Sees ist alles miteinander verknüpft. Der "große[] Zusammenhang der Dinge“ (DS 263), wie es Melusine einmal formuliert, ist es auch, was Dubslav von Stechlin als Wahlprogramm angeboten hat: eine Form des Erzählens, die eine Verknüpfung der Elemente vornimmt und in diesem Sinn eine Ordnung der Dinge garantiert.

So offen diese Haltung auch zu sein vorgibt - bestätigt durch die Opposition zu den ,petrefakten' Figuren Adelheid, Katzler, Gundermann und anderen -, so sehr bleiben die „Gesinnung“ und das „Herz“ doch einem bestimmten Habitus vorbehalten, der das formale Prinzip mit Inhalt füllt. ${ }^{177}$ „Herz“ und „Gesinnung“ gehören stets zu einer gewissen sozialen Herkunft und einem Kontext, wie er

gestellt werden. Sie haben jetzt die Freiheit, ihre Fähigkeiten nach allen Seiten hin und auf jedem Gebiete zu bethätigen." (DS 264) Siehe Kap. 1.2.3 Dynamisierung der Ordnung (Simmel), S. 21ff. oben.

177 Vgl. dazu Liselotte Grevel: „Im Grundtenor des Romans dominiert somit, ungeachtet, beziehungsweise gerade im Rahmen der ambivalenten Grundstruktur, eine Wertvorstellung, die in der lutherischen Tradition mit ihren Postulaten der göttlichen Gnade, der Demut, Beständigkeit und einer volkstümlichen Spontaneität verwurzelt ist.“ Grevel, „Das Alte und das Neue“, 533. Für eine Position, die das Gesellschaftsanalytische des Stechlin betont, vgl. Nottinger, Fontanes Fin de Siècle. 
an Dubslav von Stechlin exemplifiziert ist. Dies lässt der Text an der negativen Darstellung des Vierten Standes und der Landbevölkerung erkennen. Explizit durch die Darstellungsweise des alten Tuxen und dem Umstand, dass sie dem korrumpierten Torgelow zur Wahl verhelfen; implizit in der krassen Unterrepräsentation dieses Milieus in quantitativer wie auch qualitativer Hinsicht. Die "Gesinnung" und das "Herz" fallen also wiederum auf den Habitus des Privilegierten zurück.

Gleichzeitig darf nicht vergessen gehen, dass Dubslav von Stechlin seine Position nur auf Pump aufrechterhalten kann. Baruch und Isidor Hirschfeld, die jüdischen Geldleiher, und die Schwester Adelheid, die ihre Pfründe besser zu sichern mag, ermöglichen erst Dubslavs repräsentative Lebensweise. Die richtige "Gesinnung" vermag sich nur in einem gewissen Umfeld zu entfalten, zu dessen Sicherung sie Kompromisse eingehen muss, die ihr streng genommen widersprechen. ${ }^{178}$

\subsection{Der Ausbruch - kontrollierte Ambivalenz?}

Was alle Verfahren Fontanes „ängstliche[r] Moderne“ ${ }^{\text {“179 }}$ verhindern wollen, ist das Ausbrechen aus der bisherigen Ordnung. Um die Frage beantworten zu können, ob sich die alte Ordnung an der Macht halten kann mittels der beschriebenen Strategien oder ob die narrativen Maßnahmen nicht eher ein Überdecken der schon vorhandenen Unordnung bezwecken, ob sie also eine glatte Oberfläche herstellen, unter der sich tiefgreifende Umwälzungen umso wirkungsvoller entfalten können, bietet es sich an, die Figurationen des Ausbruchs im Stechlin zu untersuchen.

\subsubsection{Die unlesbare Botschaft}

Als Armgard und Woldemar gegen Ende des Romans auf ihrer Hochzeitsreise bei Capri weilen, betrachten sie den Vesuv im Abendlicht. Noch hat sie die Nachricht vom Tod Dubslav von Stechlins nicht erreicht.

178 In Bertolt Brechts Der gute Mensch von Sezuan, in dessen Motivanlage ein halbes Jahrhundert später Parallelen zum Stechlin zu finden sind, ist es Shen Te, die, um gut sein zu können, den bösen Vetter Shui Ta erfinden muss. Im Stechlin muss Dubslav, um seine „Gesinnung“ in der schon von der Moderne geprägten Zeit noch ausleben zu können, sein Geld bei denjenigen leihen, die seiner „Gesinnung“ spotten. Was bei Brecht verstärkt und auf eine Person übertragen ist, ist beim Stechlin noch auf mehrere Figuren verteilt, stark verschleiert und gehorcht einer ganz anderen politischen Intention.

179 So der Titel, unter den Gerhart von Graevenitz seine ausführlichen Studien zu Theodor Fontane stellt: Vgl. Graevenitz, Theodor Fontane. 
Von Sorrent kamen Fischerboote herüber, die Fischer sangen, und der Himmel war klar und blau; nur drüben aus dem Kegel des Vesuv stieg ein dünner Rauch auf und von Zeit zu Zeit war es, als vernähme man ein dumpfes Rollen und Grollen.

„Hörst du's?“ fragte Armgard.

„Gewiß. Und ich weiß auch, daß man einen Ausbruch erwartet. Vielleicht erleben wir's noch.“

„Das wäre herrlich.“

„Und dabei“, fuhr Woldemar fort, „komm” ich von der eitlen Vorstellung nicht los, daß, wenn's da drüben ernstlich anfängt, unser Stechlin mitthut, wenn auch bescheiden. Es ist doch eine vornehme Verwandtschaft." (DS 382)

Worauf Woldemar hier anspielt, ist die von ihm vielfach erwähnte Beziehung des Stechlinsees mit tektonischen und gesellschaftlichen Verschiebungen. Seiner Theorie entsprechend müsste ein Vulkanausbruch des Vesuv bis zum Stechlin wirken. Im Umkehrschluss müsste der Vesuv auch Ereignisse repräsentieren, die beim See Stechlin geschehen, so dass also der Rauch des Vesuv auf den Tod des Vaters hinwiese. Der See Stechlin als Globalisierungssymbol scheint jedoch nicht recht zu funktionieren. Zwar lässt sich eine hochgradig verschlüsselte Information aus dem Gesang der Fischer decodieren, die den Tod Dubslavs ankündigt: „Tre giorni son che Nina, che Nina, / In letto ne se sta ..." (DS 383). ${ }^{180}$ Armgard und Woldemar können diese Nachricht jedoch nicht mehr entschlüsseln. Sie gehören als ,junge Stechlin-Generation auch in dieser Hinsicht einer neuen, prosaischeren Zeit"181 an, die zwar die modernen Kommunikationsmittel, wie die zahlreichen Telegramme, verwenden, nicht aber jene aus mystisch-archaischer Zeit lesen können. ${ }^{182}$

180 Korrekt ins Deutsche übersetzt singen die Fischer: „Drei Tage sind es, daß Nina in ihrem Bett geblieben ist“. Das Lied ist ein Klagegesang über eine Frau, die sich in Gefahr befindet, sich zu Tode zu schlafen. Vgl. dazu die aufschlussreiche Analyse und die Recherche zu den verschiedenen Übersetzungen und Liedvorlagen bei Karl Pestalozzi, „Tre giorni son che Nina ...' Zu einem rätselhaften Zitat im 45. Kapitel des ,Stechlin“, in Gottfried Keller und Theodor Fontane. Vom Realismus zur Moderne, hg. von Ursula Amrein und Regina Dieterle (Berlin, New York: De Gruyter, 2008), 127-145.

181 Pestalozzi, 141.

182 Die Bedeutung der Kommunikation und Kommunikationsmittel im Stechlin ist augenfällig. Von Dubslavs Skepsis gegenüber dem Telegramm, das in der Regel negative Nachrichten übermittelt, zur Funktion des Telefons, das nur in Bezug auf den See Verwendung findet, bis zum ausführlichen Brief sind die verschiedenen Medien jeweils unterschiedlich konnotiert. Vgl. Eda Sagarra, „Kommunikationsrevolution und Bewußtseinsänderung. Zu einem unterschwelligen Thema bei Theodor Fontane“, in Theodor Fontane. Am Ende des Jahrhunderts, hg. von Hanna Delf von Wolzogen, Bd. 3: Geschichte, Vergessen, Großstadt, Moderne, 3 Bde. (Würzburg: Königshausen \& Neumann, 20oo), 105-118.

Eckehard Czucka führt die Sprachkritik im Stechlin auf die Fehleranfälligkeit und Unzuverlässigkeit der technisierten Kommunikation in Telegramm und Brief zurück: „Die 
Unabhängig und unberührt von diesem Klagegesang sehen Armgard und Woldemar einem möglichen Ausbruch des Vulkans freudig entgegen. Sie imaginieren den Ausbruch als gefahrloses Spektakel, dem beizuwohnen sie vergnügen würde. Genauso wie es die moderne Tourismusindustrie tut, die Armgard und Woldemar Ausflüge bis zum Kraterrand per Luftseilbahn anbietet. ${ }^{183}$

Der Weckruf des zitierten Lieds, die Bitte, die schlafende Nina zu wecken, lässt sich auch selbstreferenziell deuten. Woldemar und Armgard sollen aufwachen für die Zeichen der Zeit und das Sensorium für Hinweise auf Kommendes schärfen. Nicht zuletzt ist damit auch die Befürchtung verknüpft, die Botschaft des Romans selbst, der ja auch Der Stechlin heißt und im Austausch mit zahllosen anderen Werken steht, würde nicht entschlüsselt, ja nicht einmal als Botschaft erkannt werden. ${ }^{184}$ Stattdessen scheinen Armgard und insbesondere Woldemar kaum mehr gewillt, den "großen Zusammenhang“" (DS 263) sehen zu wollen, dessen Vergessen schon bei Melusines Erwähnung desselben mit dem Tod konnotiert ist. ${ }^{185}$

Mit der Unfähigkeit und vielleicht auch dem Unwillen Woldemars, die Zeichen des Vesuv zu lesen, wird der Stechlin zu einem leeren Symbol. In dieser Hinsicht weist er durchaus Anklänge an Franz Kafkas Kommunikationsparabeln und das leere Zentrum in Robert Walsers Jakob von Gunten auf. Der Unterschied insbesondere zu Kafka jedoch ist, dass bei Fontane die Botschaft

Gesellschaft in Fontanes Stechlin erscheint in der Darstellung als eine, die in ihrem Zusammenhalt und in ihrem Gefüge von einer instrumentalisierten Kommunikation zutiefst verstört ist." Eckehard Czucka, „Faktizität und Sprachskepsis. Fontanes ,Stechlin“ und die Sprachkritik der Jahrhundertwende", in Theodor Fontane. Am Ende des Jahrhunderts, hg. von Hanna Delf von Wolzogen, Bd. 2: Sprache, Ich, Roman, Frau, 3 Bde. (Würzburg: Königshausen \& Neumann, 2000), 34.

183 Zur Geschichte des Vesuv und dessen Entwicklung zu einer Touristenattraktion um die Jahrhundertwende vgl. Dieter Richter, Der Vesuv. Geschichte eines Berges (Berlin: Wagenbach, 2007).

184 Darauf weist auch Barbara Naumann hin: „Doch alles Reden bei Fontane ist schließlich und endlich Roman. In der letzten Szene des Romans tritt die Schrift als Schrift hervor und verweist damit auf den Text selbst, und zwar in einer bei Fontane seltenen, selbstreflexiven Weise. Deshalb ist der Schluß des Romans so vieldeutig, wenn er auch eindeutig in die Zukunft, in die Utopie (des Gesprächs) und in die Utopie des Bundes im Geist der Liebe verweist. [...] Es lebe der Roman Stechlin; oder anders: es lebe dieser Roman und: es lebe der Roman.“ Naumann, „Schwatzhaftigkeit“, 24. Hervorhebung i. O. Diese Selbstreflexivität verknüpft Kramer mit dem Autor Fontane, der sich so selbst Unsterblichkeit wünsche. Kramer, „Der große Zusammenhang der Dinge“, 192.

185 Siehe Kap. 2.6 „Gesinnung“, „Herz“ und „ein ewig Gesetzliches“. Die Ordnung des Stechlin, S. $76 \mathrm{ff}$. oben. 
in ihrem semantischen Gehalt deutlich ist und nur von den Figuren nicht wahrgenommen wird. Der Leser kann die Bedeutung im Stechlin ohne Weiteres entschlüsseln, während er bei Kafka die Aporie der Botschaft festzustellen hat. Diese Überlegung rückt Woldemars Rede vom Stechlin und dessen, vornehmer Verwandtschaft' in ein anderes Licht, insofern er diese Verwandtschaft nur mehr als mythische Geschichte sieht, gleichsam als narrativen Reflex, mit der er sich und seine Herkunft zu schmücken weiß.

\subsubsection{Revolution}

Mit „Ausbruch“ wird nicht nur auf die bevorstehende Eruption des Vesuv referiert. In den insgesamt sieben Mal, in denen das Wort im Stechlin auftaucht, wird es im Kontext von Krieg und Konflikt, Vulkaneruptionen und explizit auch im Zusammenhang mit sozialen Aufständen verwendet. Letzteres wird verstärkt durch weitere Symboliken, wie derjenigen des roten Hahns. Woldemar erklärt Melusine, als sie und ihre Schwester dem Stechlin einen Besuch abstatten:

Er [der See Stechlin; L. G.] steht mit den höchsten und allerhöchsten Herrschaften, deren genealogischer Kalender noch über den Gothaischen hinauswächst, auf du und du. Und wenn es in Java oder auf Island rumort oder der Geiser mal in Doppelhöhe dampft und springt, dann springt auch in unserm Stechlin ein Wasserstrahl auf, und einige (wenn es auch noch niemand gesehen hat), einige behaupten sogar, in ganz schweren Fällen erscheine zwischen den Strudeln ein roter Hahn und krähe hell und weckend in die Ruppiner Grafschaft hinein. Ich nenne das vornehme Beziehungen. (DS 131)

Trotz der offensichtlichen Konnotationen von Revolution, Aufstand und nahender Sozialdemokratie nimmt kein Stechliner diese Anzeichen ernst. ${ }^{186}$ Bezeichnet Woldemar die Beziehungen als ,vornehm' aus reiner Ignoranz, in der sich schon eine modernistische Dekadenz ankündigt? ${ }^{187}$ Oder erkennt er die revolutionären Tendenzen, sieht darin aber keine Gefahr, die ein Handeln seinerseits forderte?

186 Adelheid dagegen fürchtet sich schon vor den roten Strpmpfen Agnes' (vgl. DS 350). Vgl. auch Amberg, „Poetik des Wassers“, 553; auf die Bedeutung der Farbe Rot, gerade bei den roten Dächern der Globsower Arbeitersiedlungen weist hin: Eric Miller, „Die roten Fäden des roten Hahns. Zu einem Motivkomplex im ,Stechlin“', Fontane-Blätter, Nr. 67 (1999): 91-105.

187 Dass sich bei Fontane der Übergang zur Décadence abzeichnet, zeigt grundlegend: Nottinger, Fontanes Fin de Siècle. 
Bei Czako spielt die Ironie mit, wenn er diese ,Verwandtschaft' des Sees Stechlin anspricht. Gleich beim ersten Treffen mit Dubslav von Stechlin fragt er nach dem ominösen Gewässer und dessen revolutionärem Gehalt. ${ }^{188}$

\begin{abstract}
„Dieser merkwürdige See, dieser Stechlin! Und da frag ich mich denn unwillkürlich (denn Karpfen werden alt; daher beispielsweise die Mooskarpfen), welche Revolutionen sind an diesem hervorragenden Exemplar seiner Gattung wohl schon vorübergegangen? Ich weiß nicht, ob ich ihn auf hundertfünfzig Jahre taxieren darf, wenn aber, so würde er als Jüngling die Lissaboner Aktion und als Urgreis den neuerlichen Ausbruch des Krakatowa mitgemacht haben. Und all das erwogen, drängt sich mir die Frage auf ..."

Dubslav lächelte zustimmend.

„... Und all das erwogen, drängt sich mir die Frage auf, wenn's nun in Ihrem Stechlinsee zu brodeln beginnt oder gar die große Trichterbildung anhebt, aus der dann und wann, wenn ich recht gehört habe, der krähende Hahn aufsteigt, wie verhält sich da der Stechlinkarpfen, dieser doch offenbar Nächstbeteiligte, bei dem Anpochen derartiger Weltereignisse? Beneidet er den Hahn, dem es vergönnt ist, in die Ruppiner Lande hineinzukrähen, oder ist er umgekehrt ein Feigling, der sich in seinem Moorgrund verkriecht, also ein Bourgeois, der am andern Morgen fragt: ,Schießen sie noch?"“ (DS 25f.)
\end{abstract}

Dies ist nichts anderes als eine verkappte Frage danach, wie sich Dubslav im Fall einer Revolution zu verhalten gedenke. Wird er sich verstecken, feige auf den eigenen Vorteil bedacht, eben wie der "Bourgeois“ oder in der einen oder anderen Form mitwirken? ${ }^{189}$

Dubslav von Stechlin stellt diesen zwei Haltungen eine dritte gegenüber, nämlich diejenige des Ausharrens: „Wir verkriechen uns nämlich alle.“ (DS 26) Wie der Karpfen solle man in der warmen und gemütlichen Stube den Sturm abwarten. So könne man die Zeit würdevoll und standesgemäß überstehen, behäbig und zufrieden in der realistisch-bürgerlichen Behaglichkeit des Adels. Die ganze Szene trägt deutlich ironische Züge, insbesondere wenn mitbedacht wird, dass einige solcher Karpfen soeben verspeist werden. Worauf Dubslavs Haltung jedoch hinausläuft, ist wiederum die ewige Gesetzlichkeit des „Herzens" und der "Gesinnung“, zu der auch jene gelassene Ironie

188 Vgl. dazu Dubslavs Bemerkung: „Das andere giebt es wo anders auch, aber der See ... Lorenzen erklärt ihn außerdem noch für einen richtigen Revolutionär, der gleich mitrumort, wenn irgendwo was los ist. Und es ist auch wirklich so." (DS $5^{\circ}$ ) Dubslav nennt den See auch sein "pièce de résistance" (DS 50 ).

189 Bekanntlich hat Fontane in seinen jüngeren Jahren selbst an den Berliner Barrikadenkämpfen 1848 mitgemischt, wobei das Ausmaß seiner Involviertheit von ihm unterschiedlich beurteilt wird. Vgl. Dietmar Storch, „Theodor Fontane - Zeuge seines Jahrhunderts“, in Fontane-Handbuch, hg. von Christian Grawe und Helmuth Nürnberger (Stuttgart: Kröner, 2000), 103-191. 
gehört, die sich in der Rede vom Karpfen anzeigt: Die Ordnung des Herzens und der richtigen "Gesinnung" ist über Revolutionen erhaben und wird diese überdauern.

Gelassenheit gegenüber möglichen Ausbrüchen wird auch mit dem Romanende demonstriert. Im schon zitierten Brief, den Melusine an Lorenzen schreibt, heißt es: „[E]s ist nicht nötig, daß die Stechline weiterleben, aber es lebe der Stechlin." (DS 387, Hervorhebung i. O.) Damit ist ein Bogen zum Anfang des Romans geschlagen, in dem die Einheit von Landschaft, politischem System und "Gesinnung" beschworen wird. Der Schluss formuliert noch einmal ein nachdrückliches Argument für diese Ordnung. In der Ideologie des ewig wiederkehrenden Gesetzes des Alten und des Neuen, den Werten des Herzens, der Angemessenheit und Ausgeglichenheit wird auch verständlich, weshalb die Konsequenzen von Handlungen und Entwicklungen im Roman kein großes Gewicht haben: Es gibt Wichtigeres als den historischen Wandel. Nichtsdestotrotz ist es erstaunlich, mit welcher Sorglosigkeit der Erzähler Konflikte und Umbruchsituationen andenkt und zuspitzt, um sie dann in einer Harmonie aufgehen zu lassen, die gerade nicht aus einer Lösung des Konflikts entsteht.

Dass Dubslav von Stechlin keine Position bezieht, mag ihn mitverantwortlich machen für den Niedergang des Alten. ${ }^{190}$ Doch ist nun jenes „Stechlinsche“, die ewig wiederkehrende Ordnung, die "Gesinnung“, die Rede vom „Herzen“ bloße Beruhigungsstrategie einer dekadenten Klasse? Ist es ein weiteres inflationäres Bonmot oder nimmt der Roman tatsächlich Position für es ein?191 Wie ist also jene ,Botschaft' des Stechlin zu deuten, der bedauert, dass sie nicht mehr verstanden wird?

Krippenstapel trägt, als er Armgard und Woldemar nach ihrer Hochzeitsreise vom Bahnhof abholt, um sie zum aufgebahrten Dubslav von Stechlin zu fahren, einen „Vatermörder" (DS 384). Die damals schon veralteten hohen Kinnkragen können als Hinweis gedeutet werden, dass sich die Machtübergabe

190 So argumentiert Bowman, „Fontane's ,Der Stechlin“', 888-891.

191 Vgl. dazu Nibbrig zu Effi Briest, das genauso zum Stechlin passt: „Die Öffentlichkeit des Gesprächs bietet standpunktloser Subjektivität im leeren Gehäuse von Phrasen nur scheinbar einen Unterschlupf. Die souveräne Geste liberalen Geltenlassens von allem und jedem verdeckt eine gefährliche Indifferenz. [...] Die angebliche ,Menschlichkeit des Unverbindlichen treibt Fontane durch nichts anderes als ihre Darstellung an die Grenze ihrer Kritisierbarkeit. Das Angebot eines Schweigeraums aber, in dem die Figuren, neben ihrem gesellschaftlichen Sprachverhalten und in kritischer Wendung dagegen, authentisch sein könnten, enthüllt zugleich eine politische und ideologische Implikation der liberalen Grundhaltung: die schweigende Mehrheit durch einen Regreß auf einen Bereich privater Innerlichkeit, unter Abspaltung vom öffentlichen Rede- und Handlungsraum, still und regierbar zu halten." Christiaan L. Hart Nibbrig, Rhetorik des Schweigens. Versuch über den Schatten literarischer Rede (Frankfurt am Main: Suhrkamp, 1981), 122. 
doch nicht so harmonisch und harmlos abspielen kann. Vor diesem Hintergrund verliert Woldemars Überhören der Botschaft der singenden Fischer und des Vesuv etwas von seiner Unschuld und wird zu einem bewussten Akt der Ignoranz und Teilnahmslosigkeit. Das Paar fährt tatsächlich seltsam ungerührt von seiner Hochzeitsreise zurück. Die alte Welt, für die Dubslav steht, ist durch die Ignoranz, wie sie Woldemar insbesondere dem Vierten Stand gegenüber an den Tag legt, gefährdet - Agnes als ,tickende Zeitbombe der Revolution wird nicht dadurch entschärft, dass sie in ein Erziehungsheim gesteckt wird. In diesem Sinn lässt sich - drastisch formuliert - von einem Mord an einer Welt sprechen, die sich nicht über ihre Herrschaftsstruktur, den Adel und die Monarchie definiert, sondern über die „Gesinnung“ und das „Herz“ jener größeren Ordnung. ${ }^{192}$ Darin steckt zum einen die utopische Ansicht, dass die alte Welt Dubslavs bei angemessener Umsicht weiterbestehen könne und dass entsprechend ihr Niedergang nicht zwingend sei. Zum anderen ist die Idealität des Stechlinschen zu bedenken, die, wie gezeigt, im Roman immer wieder untergraben und hinterfragt wird. ${ }^{193}$

Unter der glatten Oberfläche lauert das Gefährliche, das weder von den Alten noch den Neuen gesehen werden will. ${ }^{194}$ Sinnbild dafür ist der See

192 Vgl. dazu Martina Klemm: „Somit steht Armgard für den Stillstand, Agnes ist dagegen der Ausbruch, die Revolution, während Melusine die Evolution verkörpert, das Fließende. Woldemar hat nun die Wahl: Welche Schwester will er heiraten? Wie will er Agnes behandeln? Woldemar entscheidet sich für Armgard und damit für den Status Quo. Er verpasst die Gelegenheit, mit Melusine eine offene Haltung für Neuerungen einzunehmen. Agnes will er sich selbst überlassen, das sei zu ihrem eigenen Besten. Damit verkennt er die gesellschaftliche Situation seiner Zeit: Der vierte Stand drängt nach Veränderungen. Man kann ihn nicht länger ignorieren, ohne auf eine Katastrophe zuzusteuern." Martina Klemm, „Die Bedeutung der Verkehrsmittel in Theodor Fontanes ,Der Stechlin“, in Theodor Fontane. Dichter des Übergangs. Beiträge zur Frühjahrstagung der Theodor Fontane Gesellschaft 2010, hg. von Patricia Howe (Würzburg: Königshausen \& Neumann, 2013), 121.

193 In einer Analyse von Dubslavs Tod arbeitet Mecklenburg Elemente der Desillusionierung im Stechlin heraus und betont ebenfalls dessen Künstlichkeit: „Fontanes poetischer Realismus [versucht] den unüberspringbaren Graben zwischen Fiktion und Wirklichkeit nicht illusionshaft zuzuschütten“. Norbert Mecklenburg, Theodor Fontane. Romankunst der Vielstimmigkeit (Frankfurt am Main: Suhrkamp, 1998), 316.

194 Die Oberfläche ist für Gerhart von Graevenitz für den Stechlin zentral: „Fontane hat im Stechlin seine eigene Anschauung vom neuen Überschuß, von der neuen Dominanz der Oberfläche gestaltet. Der Roman beginnt unübersehbar mit einer Fläche. Der See mag tief sein, er mag ein Globalisierungssymbol mit weitreichenden Unterwasserverbindungen sein. Er ist zuerst einmal eine vegetabilisch gerahmte Oberfläche, deren Tiefe und globale Verbindung unsichtbar bleiben, deren Tiefenbewegungen überliefert oder möglich, in beiden Fällen imaginär sind. Die einzige Veränderung dieser Oberfläche, die das Erzählen 
Stechlin. Beim Besuch der Barbys in Stechlin ist dieser zugefroren. Melusine gibt sich enttäuscht, sie hätte gern den See gesehen, von dem Woldemar so viel zu berichten wusste. Dubslav von Stechlin hält dagegen, dass bloß das Eis den See unspektakulär erscheinen lasse: „Das Eis macht still und duckt das Revolutionäre." (DS 259) Er schlägt vor, ein Loch hineinzuschlagen, um das Wilde des Sees sichtbar zu machen, eventuell würde sich dann auch der rote Hahn zeigen: „[D]er Hahn, wenn er nur sonst Lust hat, kommt aus seiner Tiefe herauf." (DS 259) Diese Vorstellung jedoch ist mit Angst verbunden. Melusine will „kein Eingreifen ins Elementare“ aus Furcht, „eine Hand führe heraus und packte mich." (DS 259) Damit benennt sie präzise die Ignoranz, die in der dauernd verwendeten ironischen Rede durchscheint. Sie weiß, dass sich unter der Oberfläche etwas Kraftvolles verbirgt und ist sich der Strategie des Übersehens bewusst, im Gegensatz zu den anderen, die so tun, als würden sie hinschauen, in Tat und Wahrheit aber gerade nichts tun.

\subsection{Die prekäre Inszenierung des „Gesetzlichen“. Fazit}

Theodor Fontane diskutiert in Der Stechlin Strategien im Umgang mit dem Ordnungsproblem der Moderne und weist - auch in dieser Hinsicht - weit über die Jahrhundertwende hinaus. Grundlage der Ordnungskonzeption im Stechlin ist eine Generationenentwicklung, welche ein allgemeines „Gesetzliches, das sich vollzieht", als Lebenszyklus apostrophiert. In diesen Lebenszyklus sind eine Standeshierarchie und Geschlechtertypologie implementiert, in denen das patriarchalische System, das sich durch die richtige Gesinnung auszeichnet, reproduziert wird. Dass Ordnung auf dieser abstrakten und allgemeinen Ebene thematisiert wird, mag schon darauf hinweisen, wie problematisch Ordnung geworden ist.

Diese Erzählordnung als Ordentlichkeit des Romans ist in verschiedenen Bereichen auf die enge Kontrolle von Ambivalenz angewiesen. Auf einer verfahrenstechnischen Ebene wirkt der Erzähler als ordnende Instanz, die sich souverän zu inszenieren vermag. Mittels Separierung von Schauplätzen und Handlungssträngen sowie straffen Überleitungen ordnet er das Geschehen. Ambivalenz wird zielgerichtet und in engen Grenzen eingesetzt, um die Geschichte voranzutreiben und Spannung zu erzeugen. Etwaige

sichtbar macht, ist ihr winterliches Zufrieren. Der See wird vollends zur undurchdringlichen Oberfläche. Und die Idee, die geschlossene Oberfläche gewaltsam zu öffnen, verursacht Angst und Schrecken." Graevenitz, Theodor Fontane, 729f. Hervorhebung i. O. 
Unsicherheiten auf der story-Ebene werden vom discourse übergangen. So entsteht eine glatte Oberfläche, deren Künstlichkeit jedoch deutlich hervortritt.

Auf inhaltlicher Ebene manifestiert sich die Ambivalenz darin, dass weder die positiv konnotierten Figuren in der komplexen erzählten Welt eindeutige Positionen einnehmen noch vom Erzähler solche eindeutigen Positionen etabliert werden. Das Alte und das Neue werden nicht eindeutig als gut oder schlecht dargestellt, ebenso ist die Wahl Woldemars zwischen Armgard und Melusine durchaus ambivalent. Dubslav von Stechlin selbst ist vom Paradox angetan, was sich in der vielfach ironisch gewendeten Figurenrede äußert, wie auch die Figuren selbst vielfach in Spiegelfiguren potenziert sind. Die alte Ordnung vertritt Dubslav letztlich auf Pump: Er kritisiert sowohl rigorose Positionen des Alten als auch den modernen Kapitalismus und ist selbst davon abhängig. Dies zeitigt eine ambivalente Bewertung seines Ordnungsverständnisses. Trotz dieses ambivalenten Grundtenors des Romans ist deutlich, dass die favorisierte Ordnung eine Tendenz aufweist, die den Habitus eines menschlich-nachsichtigen Adels belohnt.

Die Komplexität des Figurenarsenals und die Vielfalt der verhandelten Diskurse und Positionen im Stechlin sind bemerkenswert. Im Kontrast zu dieser Vielfalt sticht die souveräne und geordnete Erzählweise sowie die konsequente Symbolik hervor. Zahlreiche intra- und intertextuelle Anspielungen erzeugen ein dichtes Geflecht an Referenzen, deren Funktion es ist, dem Inhalt Kohäsion und Kohärenz zu geben. Auch in der detaillierten Struktur der Kapitel auf unterschiedlichen Hierarchiestufen stellt sich der Roman als ordentlicher und kontrollierter Text aus.

Die narrative Form des Stechlin demonstriert auf diese Weise eine ganz bestimmte Umgangsform mit Ambivalenz: Es ist der Versuch, mittels Narration eine eigentlich unordentlich gewordene Welt zu ordnen, im Bewusstsein um die Ambivalenz der Welt und des Unterfangens. Dem „Ordnungsschwund“ der Moderne wird mit geordnetem Erzählen begegnet. ${ }^{195}$ Im kontrollierten Erzählen soll Vertrauen in eine Ordnung erzeugt werden, die Risse nicht benennt, sie nur in ihrer Abwesenheit anwesend sein lässt und dennoch einen Zusammenhang aller Dinge postuliert. Die überdeutliche Leserführung macht zugleich die Künstlichkeit des Romans offensichtlich. Der Stechlin führt vor, wie eine kontrollierte und kontrollierende Umgangsweise mit Ambivalenzen zu einer Proliferation von Ambivalenz führt. Je ordentlicher Armgard und Woldemar werden, sich in ihrer Ehe einrichten, desto weniger kümmern sie sich um Ambivalenzen, wie sie etwa in der Figur der Agnes vor sie tritt.

195 Vgl. Blumenberg, „Ordnungsschwund und Selbstbehauptung. Über Weltverstehen und Weltverhalten im Werden der technischen Epoche“. 
Sie lesen weder die Botschaften des Sees Stechlin, noch blicken sie in die Zukunft. Ihre scheinbar so ordentliche Haltung lässt sie zu ambivalenten Figuren werden, die in dieser Hinsicht höchst modern sind und, mit Georg Simmel gesprochen, eine ,blasierte Lebenshaltung' eingenommen haben. ${ }^{196}$ So wird Der Stechlin, der am Ende des Romans gemäß Melusines Diktum leben soll, in seiner gesamten Polysemantik selbst ambivalent. Warnt Der Stechlin davor, wie narrative Ordnungsverfahren über eine letztlich machtpolitische Operationalisierung der Exklusion funktionieren? Oder wendet er diese Mechanismen zur eigenen Funktionalisierung an? Diese Spannung erzeugt der Roman und in diese Spannung stellt er sich hinein. So wird Fontanes scheinbar so souveränes Erzählen als ein im Grunde prekäres Erzählen greifbar, das auf Robert Walser und Franz Kafka vorausweist.

196 Siehe Kap. 1.2.3 Dynamisierung der Ordnung (Simmel), S. 21ff. oben. 